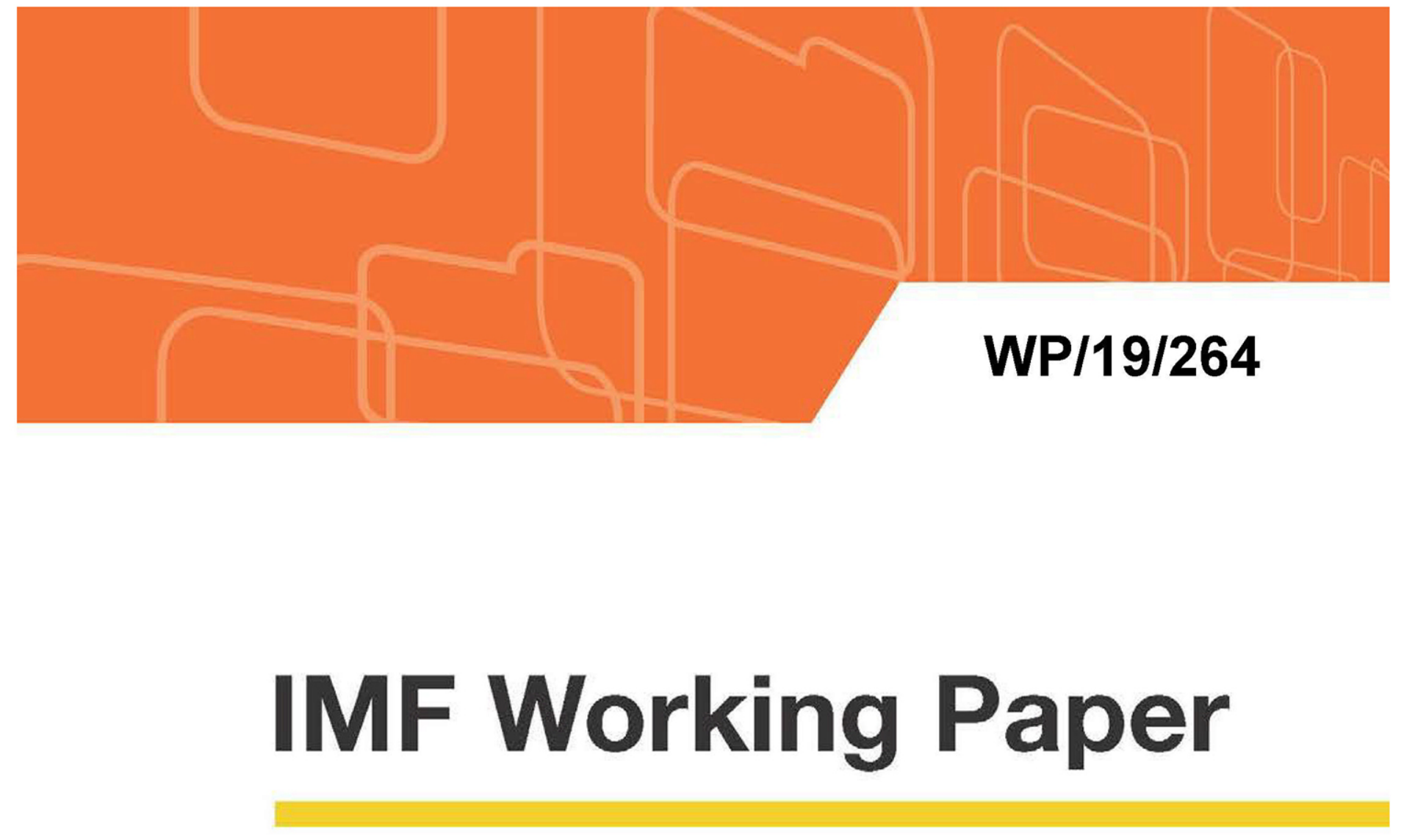

\title{
Network Determinants of Cross-Border Merger and Acquisition Decisions
}

by Tatiana Didier, Sebastián Herrador, and Magali Pinat

IMF Working Papers describe research in progress by the author(s) and are published to elicit comments and to encourage debate. The views expressed in IMF Working Papers are those of the author(s) and do not necessarily represent the views of the IMF, its Executive Board, or IMF management.

I N T E R N A T I O N A L M O N E T A R Y F U N D 


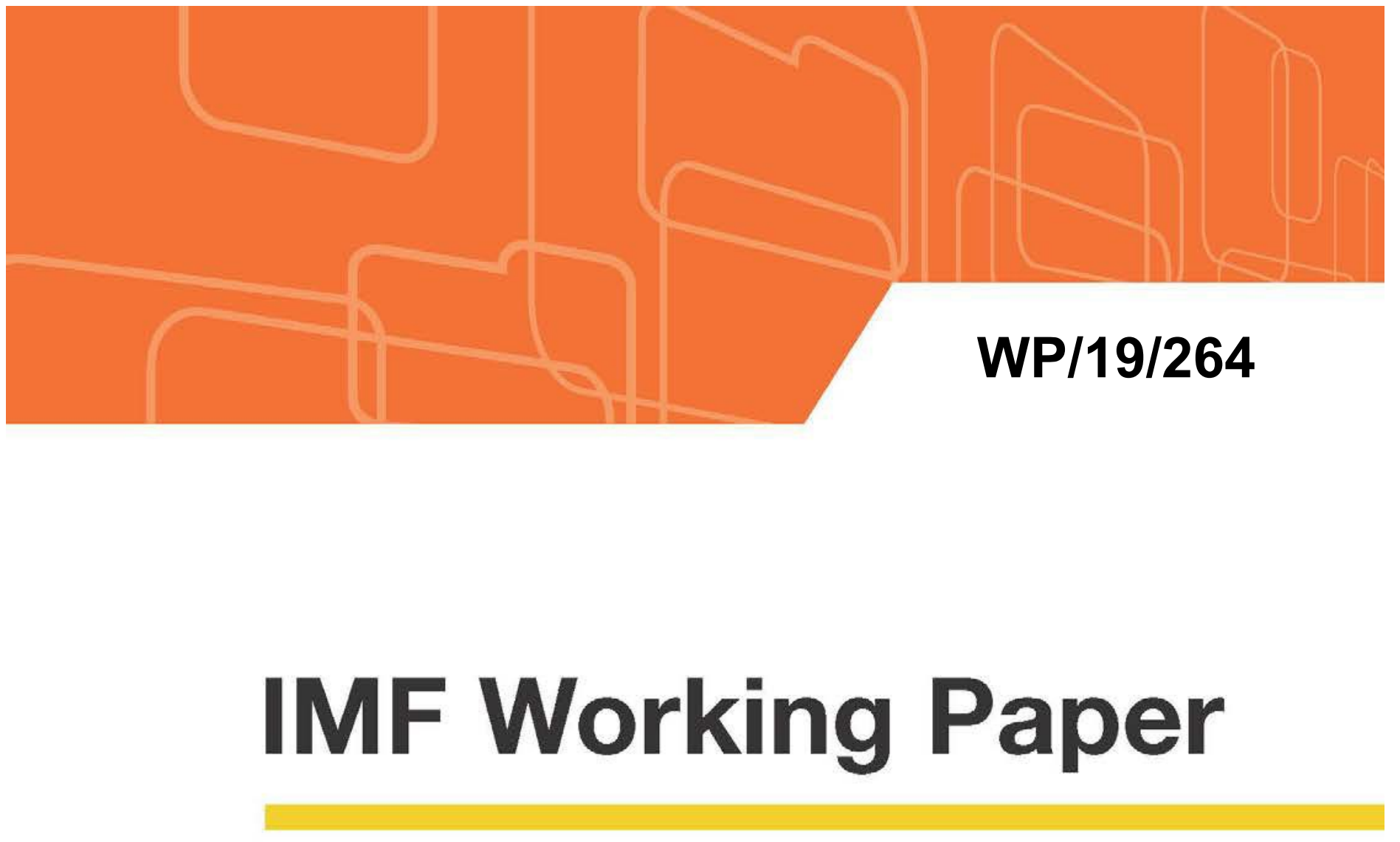

\section{Network Determinants of Cross-Border Merger and Acquisition Decisions}

by Tatiana Didier, Sebastián Herrador, and Magali Pinat

IMF Working Papers describe research in progress by the author(s) and are published to elicit comments and to encourage debate. The views expressed in IMF Working Papers are those of the author(s) and do not necessarily represent the views of the IMF, its Executive Board, or IMF management.

$$
\text { I N T E R N A T I O N A L M O N E T A R Y F U N D }
$$




\author{
IMF Working Paper \\ Institute for Capacity Development \\ Network Determinants of Cross-Border Merger and \\ Acquisition Decisions \\ Prepared by Tatiana Didier, Sebastián Herrador, and \\ Magali Pinat* \\ Authorized for distribution by Valerie Cerra
}

December 2019

IMF Working Papers describe research in progress by the author(s) and are published to elicit comments and to encourage debate. The views expressed in IMF Working Papers are those of the author(s) and do not necessarily represent the views of the IMF, its Executive Board, or IMF management.

\begin{abstract}
This paper assesses whether cross-border M\&A decisions exhibit network effects. We estimate exponential random graph models (ERGM) and temporal exponential random graph models (TERGM) to evaluate the determinants of cross-country M\&A investments at the sectoral level. The results show that transitivity matters: a country is more likely to invest in a new destination if one of its existing partners has already made some investments there. In line with the literature on export platforms and informational barriers, we find a sizable impact of third country effects on the creation of new investments. This effect is sizable and larger than some of the more traditional M\&A determinants, such as trade openness.

JEL classification: G34, D85, D83.

Keywords: Cross-Border Merger and Acquisition, Networks, Informational Effect.

Author's E-Mail Address: tdidier@worldbank.org; sherradorguzman@deloitte.ca; mpinat@,imf.org
\end{abstract}

\footnotetext{
${ }^{*}$ Tatiana Didier is Senior Economist at the World Bank, Sebastián Herrador is currently Economist at Deloitte but the paper was prepared during his time at the International Mone-tary Fund, and Magali Pinat is Economist at the International Monetary Fund. The authors would like to thank Lionel Fontagné, Luca de Benedictis, Raja Kali, Angelo Secchi, Anne-Célia Disdier, José De Sousa, Martin Cihák, Tumer Kapan, and the participants of the IMF ICD Tuesday lunch seminar for suggestions and comments. All errors and omissions are our own.
} 


\section{Introduction}

The value of worldwide foreign direct investment (FDI) has increased significantly since the early 1990s, from US $\$ 204$ billion in 1990 to US $\$ 1868$ billion in $2016^{1}$, with mergers and acquisitions (M\&A) representing a large share of total FDI (45 percent in 2016). Many observers view the rising participation of developing countries' economies in global financial flows broadly and FDI, particularly, as a potential driver of these countries' economic growth. FDI flows can not only directly ease financing constraints in recipient economies, but they can also be a major conduit of technology diffusion (both hard technologies, such as machinery and blueprints, and soft technologies, such as management techniques and information) and learning spillovers ${ }^{2}$.

This paper makes an investigation of the drivers of FDI, by focusing on cross-border M\&A transactions at the sectoral level. We examine the determinants of M\&A decisions by building on the gravity model framework. This methodology, commonly used in trade literature, has been used more recently to understand the determinants of cross-border capital flows. We build upon the existing literature by adding a novel aspect to the standard gravity equation. Largely missing in most of the current academic and policy discussion, we analyze whether the structure of the financial network influences a country's investment decision. In line with the literature on informational barriers, we investigate whether the decision to invest in a certain country depends on the relationship between its partners and the targeted country, that is, firms are more likely to invest in countries wherein partners have already invested. The motives for foreign investments may vary across sectors. Hence, we separately consider M\&As in three different sectors - primary, light manufacturing, and heavy manufacturing. Our study focuses on a large sample of 83 countries, covering more than 94 percent of total flows between 2000 and 2016 .

As a first step, we use a logit estimation to provide benchmark results characterizing the drivers of cross-border M\&A transactions. However, this methodology is unsuitable for evaluating potential dependencies among the countries

\footnotetext{
${ }^{1}$ Data from UNCTAD.

${ }^{2}$ Romer (1993) argues that the presence of multinational companies can narrow both the "object gap" (the shortage of physical goods, such as factories and roads) and the "ideas gap" (the shortage of knowledge used to create value added) in developing economies.
} 
in the network. Indeed, it is likely that M\&A decisions between an acquirer and a target are not only dependent on the characteristics of these two countries, nor solely on the characteristics linking the acquirer with the target with other countries, but also rely on other third countries. To account for high degree dependencies, we estimate exponential random graph models (ERGM) for cross-sectional data between 2000 and 2016. We also estimate temporal ERGM models (TERGM) for the 2000-2016 period, though some computational issues arise.

We find that the odds of an M\&A investment are 4.2 times higher in light manufacturing, 4.5 times higher in Primary, and 6.2 times higher in heavy manufacturing when a partner country has already invested in a new location. These odds are larger than some of the more traditional M\&A determinants, such as trade openness.

The remainder of the paper is organized as follows. Section 2 describes the relevant literature. Section 3 presents the econometric methodology. Section 4 introduces the data and some descriptive statistics. Section 5 provides the results. Finally, Section 6 summarizes and concludes.

\section{Literature Review}

This section first exposes the traditional determinants of M\&A decision and then turns to some elements of network analysis that can be found in the trade and finance literature.

\subsection{Traditional determinants of M\&A investment}

A domestic M\&A typically takes place when the management of a firm perceives the potential gain of acquiring another entity (see for example Jensen and Ruback (1983); Jarrell et al. (1988); and Andrade et al. (2001)). These gains can come from production efficiencies such as a reduction in contracting costs across firms. Mergers can be driven by the motive of achieving tax optimization or to gain market power. Furthermore, managers can take valuedecreasing acquisitions that increase their individual utility. Research on the 
determinants of M\&As also highlights the importance of intra-industrial flows. Deregulation can also play a role in M\&A activity.

Cross-border M\&As can be affected by a wider range of factors, in addition to the determinants listed above. For instance, the typical factors used to explain trade in goods can be relevant for cross-border financial investments, such as geographic distance and differences in language, currency $^{3}$, legal framework, colonial origin, and time zones. Ahern et al. (2015) argue that these frictions increase the cost associated with cross-border M\&As. Information asymmetries can also pose a major obstacle. For instance, an assessment of the valuation of targeted firms can be more difficult for foreign firms. Differences in regulations also impact cross-border M\&A decisions; Chari et al. (2009) find that developed-market acquirers benefit more from weaker contracting environments in emerging markets. Additionally, currency fluctuations impact the profitability of investments, independent of firms' fundamentals. Standard gravity model variables will be included in our setup.

Another key factor exposed by Rajan and Zingales (1998) is the importance of the state of development of financial markets. The existence of a welldeveloped market represents a source of comparative advantage for a country in industries that are more dependent on external finance; conversely, the costs imposed by a lack of financial development can impede the development of a new sector. Therefore, the level of financial development impacts not only the amount of inflow but also determines the developments of certain sectors and its concentration. We will consider the sectors in which investment are realized.

There has been a growing interest in understanding the role of trade in goods as a determinant of financial flows. The classic Heckscher-Ohlin-Mundell paradigm predicts that trade is an important factor in international capital flows. It argues that exports are based on endowments - advanced economies export capital. Additionally, the paradigm states that and trade and capital flows are substitutes. Countries invest in locations to which they cannot export their goods, thereby gaining access to their domestic markets. Consequently,

\footnotetext{
${ }^{3}$ De Sousa and Lochard (2011) find that the Economic and Monetary Union (EMU) has increased intra-EMU FDI stocks on average by around 30 percent.
} 
trade integration reduces incentives for capital to flow to capital-scarce countries.

Recent theoretical work on international investment argues that trade and capital flows can be complements rather than substitutes and that the emerging economies export capital to advanced economies (Antras and Caballero (2009); Ju and Wei (2011); Jin (2012)). A part of these effects may be rooted in firm-level motives to export and invest abroad (Greenaway and Kneller (2007); Alfaro and Charlton (2009)). Empirically, De la Torre et al. (2015) use a crosscountry sectoral gravity framework to examine the influence of trade in the decision of financial investment. Particularly, the authors include measures of comparative advantage on traded goods for source and receiver countries as dependent variables on a gravity equation for FDI. They find that advanced economies tend to invest more in sectors wherein the receiver has a comparative advantage, while the emerging and developing markets invest more in countries wherein the receiver has a disadvantage. We integrate comparative advantages of trade into the M\&A determinants.

\subsection{Network determinants of bilateral decision}

The core of this paper digs into the importance of the information barrier at the time of investing in a new country. This paper shares with Chaney (2014) the notion of information as the key friction in international relationships. As per Chaney (2014), if a certain firm exports to country $a$ in year $t$, then it is more likely to enter into a country $b$ geographically close to $a$ in year $t+1$, even if $b$ is not close to the firm. The possibility to use existing contacts to find new ones gives an advantage to firms with many contacts. This generates a fat-tailed distribution for the number of foreign contacts across firms. We apply a similar reasoning to understand factors driving a new oversea M\&A investment -if a country had invested in country $a$ in year $t$, then it is more likely to invest for the first time in country $b$ in year $t+1$, if $a$ had already invested in $b$.

Empirical work including third-country effects on FDI decisions is sparse. The "export-platform" literature (Ekholm et al. (2007), Yeaple (2003), Bergstrand and Egger (2007)) is close to our work. Export-platform refers to a situation wherein a parent country invests in a particular host country with the intention of serving "third" markets with exports of final goods from the affiliate 
companies in the host country.

Head et al. (1995) use a conditional logit estimate to examine the choice of location of 751 Japanese manufacturing plants built in the US, including a specific variable for interdependence of the location decision across all possible locations. Their estimates support the hypothesis that industry-level agglomeration benefits play an important role in the location decision. Using a sample of Japanese firms' choices of regions within European countries, Head and Mayer (2004) show that not only the potential of the host market but also the potential of markets in adjacent regions holds significance in determining location choice.

While Head et al. (1995) and Head and Mayer (2004) use a discrete choice model to assess the importance of third-country effect, such a framework imposes the independence of all the alternatives. Blonigen et al. (2007) allow a more general setup using spatial econometrics. Their study finds suggestive evidence of export-platform FDI for most industries within the developed European countries.

To estimate the network impact, we need to estimate the determinants at the country, dyad, and network levels simultaneously; this estimation is not possible with the gravity framework. Unlike the spatial model of Blonigen et al. (2007), we use an ERGM that considers the network as a conditional factor on a series of predictor terms (Erdös and Rényi (1959); Frank and Strauss (1986); Hunter and Handcock (2006)). We also use the temporal extension of the ERGM - the discrete TERGM - to analyze the dynamics of the networks (Krivitsky and Butts (2013); Krivitsky and Handcock (2014)). We focus on extra-dyadic interdependencies that arise from an "alliance" network (Cranmer et al. (2012)). When making a decision concerning oversees M\&As, firms are likely to consider not only the characteristics of their targeted country (e.g., population and area) or its relationship with them (e.g., size of the bilateral trade, border effects, and potential information asymmetries) but also what happens in other "alliances." To the best of our knowledge, the contemporaneous project of Herman (2017) is the only other paper using ERGM in international economics. Herman (2017) reestimates the traditional trade gravity model, by integrating network variables in a probit model of trade incidence and in an ERGM. He concludes that both modelizations represent a better modeling environment than the classical gravity model. 


\section{Methodology}

In lieu of the traditional setup, ERGM and TERGM allow the examination of higher level dependencies in an M\&A network. The observed M\&A network is considered one of the many networks that had the potential to realize. It represents a realization of a random draw from a distribution of all the possible M\&A networks. Statistical inferences will give information on the determinants of the realized network.

\subsection{Exponential random graph model}

To estimate the impact of the network on an M\&A decision, we use an ERGM. ERGMs are a general class of models based in exponential-family theory that specify the probability distribution of random networks. Through ERGM, it is possible to identify factors that maximize the probability of the emergence of a network with similar properties as the structure of the observed network.

In an ERGM, the probability to observe a network $g$ depends on an associated vector of statistics $S(g)$ that might include, for instance, the density of the network, number of mutual links, or number of triangles. The general form of the probability of realization of a network is the following:

$$
P_{\beta}(Y=y \mid \beta)=\frac{\exp (\beta . S(y))}{\sum \exp \left(\beta^{\prime} . S\left(y^{\prime}\right)\right)}
$$

where $Y$ is the random variable for the state of the network (with realization y), $\beta$ is a vector of model parameters, $S(y)$ the vector of model statistics for network $y, \exp (\beta . S(y))$ the probability of observing $y$, and the denominator $\sum \exp \left(\beta^{\prime} . S\left(y^{\prime}\right)\right)$ is the sum of all other possible networks. The value of $\beta$ should be interpreted as the log-odds impact of the variable on the appearance of a tie between two countries.

There are two main challenges in estimating ERGMs. The first is a computational one. To estimate the likelihood of a given network, we need to estimate the likelihood of other networks as well (denominator in the probability equation). Estimating the universe of all other networks challenges the current computational possibility, as the number of possible networks grows exponen- 
tially with the number of nodes. To deal with this issue, we use the Markov Chain Monte Carlo (MCMC) sampling techniques to draw networks and estimate ERGMs (Snijders (2002); Handcock et al. (2003)). MCMC is based on the generation of a distribution of random graphs by stochastic simulation from a starting set of parameters, which are refined through comparison with the observed graph across iterations. The process ends once the parameters are stabilized. However, reaching convergence remains an issue for many ERGM specifications (Handcock et al. (2003); Hunter et al. (2008)).

The second challenge is in the consistency of the estimates. At the difference, with standard models, increasing the number of observations in an ERGM is not necessarily associated with an increase in the accuracy of the results. Following Jackson (2010), a necessary condition for consistency is the "non-conflicted" condition. In some small neighborhoods, the expected value of statistics must be unconstrained, that is, each realization must be jointly feasible. To respect this condition, we exclude isolate nodes from our sample. A first sufficient condition is that different parameters must distinguish themselves with different expected statistics. This is a minimal condition, because if two parameters generate too similar outputs, the realized statistics do not allow to distinguish between them. The second sufficient condition is that statistics must be appropriately normalized and concentrate around their means. If this condition is not realized, observing the statistics would not allow us to back out to a parameter.

To assess the accuracy of our prediction, we compare the structures of the simulated network and the observed network. Following Hunter et al. (2008), we compare the goodness of fit of the degree distribution, distribution of edgewise shared partners, and geodesic distribution. The closer is the simulated distribution of the observed network, the more accurate and reliable is the estimation.

\subsection{Temporal exponential random graph model}

To transition to a TERGM, we need to add a matrix to account for the dynamic. To model the transition from network $Y^{t}$ at time $\mathrm{t}$ to a network $Y^{(t+1)}$ at time $t+1$, we assume a separable TERGM. The formation and dissolution of ties occur independently from each other within each time step. Both the formation and dissolution processes are modeled as separate ERGMs. 
Let us define $Y^{+}$as the formation network generated as an ERGM. Formally,

$$
P_{\beta}\left(Y^{+}=y^{+} \mid Y^{t} ; \beta^{+}\right)=\frac{\exp \left(\beta^{+} . S\left(y^{+}\right)\right)}{\sum \exp \left(\beta^{+^{\prime}} . S\left(y^{+^{\prime}}\right)\right)}
$$

Dissolution network $Y^{-}$is generated simultaneously. Thus, formally,

$$
P_{\beta}\left(Y^{-}=y^{-} \mid Y^{t} ; \beta^{-}\right)=\frac{\exp \left(\beta^{-} . S\left(y^{-}\right)\right)}{\sum \exp \left(\beta^{-^{\prime}} . S\left(y^{-\prime}\right)\right)}
$$

The cross-sectional network at time $t+1$ is constructed by applying change $Y^{+}$and $Y^{-}$to $y^{t}$. Formally,

$$
Y^{t+1}=Y^{t} \mp\left(Y^{+}-Y^{t}\right)-\left(Y^{t}-Y^{-}\right)
$$

\subsection{Obtaining convergence}

One challenge faced in using ERGM and TERGM estimations is the difficulty to reach convergence. The following are ways to obtain converging results:

- We constrain the set of possible networks to those with the same number of ties as the observed network. This restriction ensures that only reasonable networks are used in the estimation. This eliminates unrealistic networks in which there are no ties or all nodes are connected. The coefficient of bilateral trade is then interpreted as the estimation of which countries invest in M\&As, given a fixed prevalence of ties.

- We binarized the matrix of M\&A flows and use a dummy for High Income countries instead of their GDPs.

- Using the IMF classification, we limit the set of nodes to high income and emerging/developing countries, and exclude low income economies. The sample is reduced to 83 countries, representing nevertheless more than 94 percent of global flows (see Figure 2 and Annex A1 ). 


\section{Data and descriptive statistics}

We analyze the cross-border decisions of M\&A investment. We choose M\&A investments for two reasons: 1) M\&As are long-term investments, as they mean that the acquirer takes "control of assets and operations" (UNCTAD 2000). 2) The quality of data is generally better than for other investments.

Data on M\&As are taken from the Thompson Reuter's Security Data Corporation Platinum database for operations realized between 2000 and 2016. We aggregate the data by country and obtain a bilateral database at the country level. Sectors of investment are classified using the 4-digit Standard Industrial Classification (SIC) and based on the receiving firm classification. Using network analysis terminologies, countries are represented by nodes, and M\&A outflows are represented by direct ties linking a pair of nodes. The network is binarized. Moreover, we distinguish three types of investments: in the primary sector (including agriculture, mining, and oil), in the light manufacturing sector (including food, textiles, and wood), and in the heavy manufacturing sector (including chemicals, metals, machinery, and equipment). We construct one network by sector and by year (Figure 1). 
Figure 1: Cross-border M\&A investment network by sector in 2016

(a) Primary sector

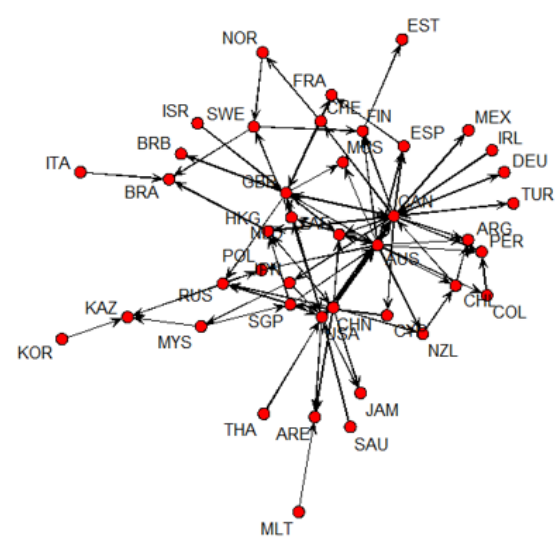

(b) Light manufacturing
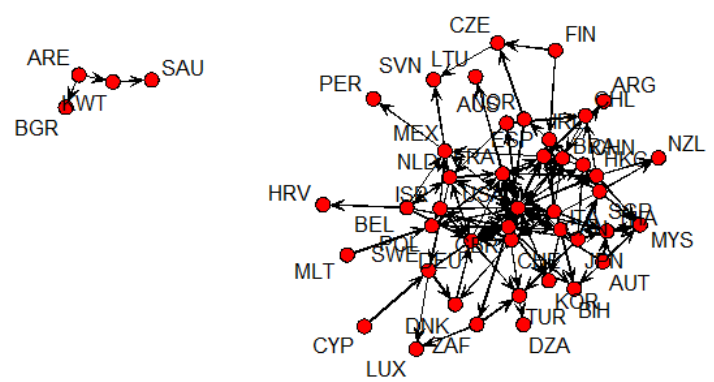

(c) Heavy manufacturing

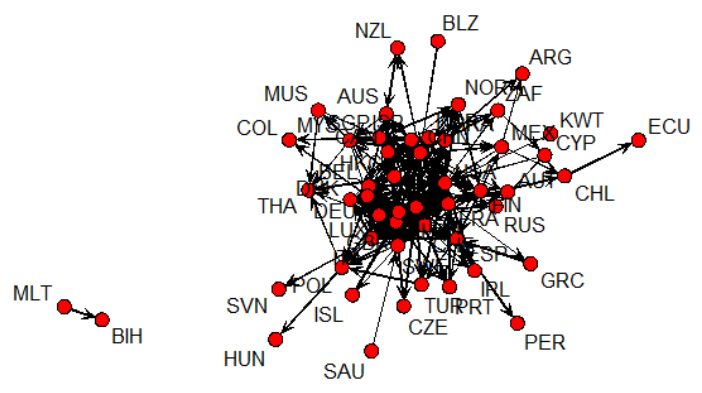

Source: Thompson Reuter's Security Data Corporation Platinum database and author's calculations. 
Figure 2: M\&A investments sample
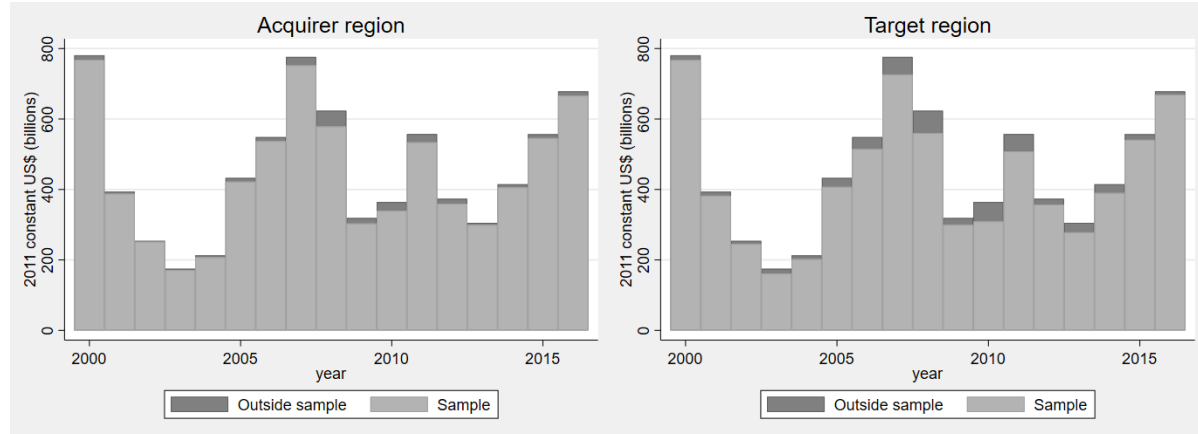

Source: Thompson Reuter's Security Data Corporation Platinum database. 


\subsection{Dyad level variables}

In recent $\mathrm{M} \& \mathrm{~A}$ literature, trade is an essential determinant. In this study, we use the concept of net relative comparative advantage (NRCA) constructed following Vollrath (1991) to understand the impact of trade on investment ${ }^{4}$. Formally,

$$
R C A_{i, j, t}=\ln \left\{\frac{X_{i, j, t} /\left(\sum_{\forall j} X_{i, j, t}-X_{i, j, t}\right)}{\frac{\left(\sum_{\forall i} X_{i, j, t}-X_{i, j, t}\right)}{\left[\left(\sum_{\forall i, j} X_{i, j, t}-\sum_{\forall j} X_{i, j, t}\right)-\left(\sum_{\forall i} X_{i, j, t}-X_{i, j, t}\right)\right]}}\right\}
$$

where $\left.X_{(} i, j, t\right)$ refers to the exports of country $i$ in industry $j$ in period $t$. The dependent variable is specified as $\log (1+$ flows $)$ in order to explicitly account for the large number of observations equal to zero. All regressions control for both fixed source and host-country effects.

We calculate the NRCA at the bilateral level for each sector and year based on bilateral exports from UN Comtrade/World Integrated Trade Solution. The dataset covers the period from 2000 to 2016 for 205 source and recipient countries. We aggregate the database to the bilateral country level using the 4-digit Standard International Trade Classification (SITC). SITC and SIC (for M\&A classification) are not directly comparable: SITC is a classification of goods, while SIC is a classification of industries. Thus, we use Eurostat's conversion tables to obtain each SITC code associated with the 4-digit SIC codes. We then aggregate the data in the three aggregate sectors.

In our analysis, we control for an exogenous variables that could impact M\&A investment. The control variables are both node-specific and dyadicspecific, and they are adapted to finance from the literature on gravity models. The controls variables are obtained from the GeoDist database of Centre d'Etudes Prospectives et d'Informations Internationales, The World Factbook of the Central Intelligence Agency, and World Development Indicators by the World Bank. We include trade openness as the sum of exports and imports. We

\footnotetext{
${ }^{4}$ Unlike the traditional definition of relative comparative advantage, Vollrath (1991)'s equation considers the market share of exporters.
} 
also include distance, longitude, and latitude (all in $\mathrm{km}$ ). We control based on differences in time zones (in hours) as they may impact financial transactions. Finally, we consider the common language, common legal origin, and colonial history.

\subsection{Network level variables}

We include two variables at the structural network level. First, we include the edges that corresponds to the number of links in the network. They can be interpreted as intercept parameters in a bilateral framework and are required in ERGM configuration (Snijders et al. (2006); Hunter (2007)).

Second, we include a measure of transitivity to represent the shared partner distribution (Hunter and Handcock (2006); Hunter (2007)). This term adds one network statistic to the model equal to the geometrically weighted edgewise shared partner (GWESP) distribution with weight parameter alpha. It measures how frequently two nodes are connected by a link as well as by an indirect connection of length 2. The significant and positive GWESP coefficient points to transitivity in the network that is beyond the transitivity that may be explained solely by nodal characteristics. This suggests that countries are more likely to realize an M\&A with countries that are also connected to one another.

The shared partner distribution is an alternative approach to counting triangles (Goodreau et al. (2009)). Two countries share a partner if both have a tie to the same country, and each shared partner forms a triangle if the original pair are tied. Unlike the census of triangles or the clustering coefficient (which produce a single measure for the whole network), the shared partner count is taken on each edge and produce a distribution of counts. The GWESP statistics is a parametric form of this count distribution; each additional shared partner has a decreasing positive impact on the probability of two countries to become partners.

The GWESP statistics is equal to:

$$
G W E S P=e^{\alpha} \sum_{i=1}^{n-2}\left\{1-\left(1-e^{-\alpha}\right)^{-i}\right\} p_{i}
$$

where $p_{i}$ equals the number of country pairs who are connected and who 
share exactly $i$ partners. This statistics includes a parameter $\alpha$, that controls for the geometric rate of decline in the effect of triad closure on tie probability for an increasing number of shared partners. We adopt a value of 0.25 for $\alpha$, standard in the literature. We explore alternative values ranging from 0 to 0.5 with relatively small impact on coefficient estimates or on the model fit.

\section{Results}

This section empirically estimates the determinants of M\&A investments, by testing the trade openness variable and gravity variables in a logit regression before estimating the potential impact of network variables with the ERGM and TERGM procedures.

\subsection{Logit estimations}

The regressions in Table 1 explore in more detail the relationship between M\&A and trade flows at the country-pair level using logit estimates ${ }^{5}$. Particularly, the regressions link $M \& A$ flows with the comparative advantages of the source and receiving countries for each of the following three sectors: primary, light manufacturing, and heavy manufacturing. The regressions also include gravity controls. The first three columns refer to a cross-country regression for 2016 , while columns (4) to (6) estimate a cross-country panel extending from 2000 to 2016.

The first pattern that emerges from Table 1 is that, even after controlling with gravity variables for common factors that can jointly drive trade and lending decisions, high-income countries tend to invest more in any of the three sector. The high-income variable is set as a proxy for the GDP acquirer because the usage of a continuous variable of GDP prevents convergence in ERGM/TERGM estimations. The countries that are more open also tend to invest more (measured as the sum of exports and imports). In 2016, an increase in one unit of the log of trade openness variable (about 2.8 percentage points increase in trade

\footnotetext{
${ }^{5}$ This procedure is not considered standard in existing literature; M\&A is usually estimated with a two-step probit, such as in Di Giovanni (2005), or by using Poisson pseudo-maximumlikelihood (PPML), such as in De la Torre et al. (2015). However, due to computational limitation, the ERGM can currently be run only on the binarized matrix. To facilitate the analysis of the additional effect of network measures, we use a logit procedure as a first step.
} 
Table 1: Estimations of M\&A determinants using Logit estimates

\begin{tabular}{|c|c|c|c|c|c|c|}
\hline & \multicolumn{3}{|c|}{2016} & \multicolumn{3}{|c|}{$2000-2016$} \\
\hline & \multirow{2}{*}{ Primary } & Light & Heavy & \multirow{2}{*}{ Primary } & Light & Heavy \\
\hline & & Manuf. & Manuf. & & Manuf. & Manuf. \\
\hline & (1) & $(2)$ & $(3)$ & (4) & $(5)$ & $(6)$ \\
\hline \multirow[t]{2}{*}{ Trade Openness $_{i}$} & $0.718^{* * *}$ & $0.766^{* * *}$ & $0.885^{* * *}$ & $0.898^{* * *}$ & $0.806^{* * *}$ & $0.946^{* * *}$ \\
\hline & $(0.11)$ & $(0.09)$ & $(0.09)$ & $(0.06)$ & $(0.04)$ & $(0.04)$ \\
\hline \multirow[t]{2}{*}{${\text { High } \text { Income }_{i}}$} & $0.859^{* *}$ & $0.885^{* * *}$ & $0.758^{* * *} *$ & $1.166^{* * *}$ & $1.137^{* * *}$ & $1.425^{* * *}$ \\
\hline & $(0.34)$ & $(0.27)$ & $(0.20)$ & $(0.17)$ & $(0.13)$ & $(0.12)$ \\
\hline \multirow[t]{2}{*}{ Net $\mathrm{RCA}_{i k}$} & $0.211^{* * *}$ & -0.166 & $-0.351^{* * *}$ & $0.0873^{* * *}$ & 0.0667 & $-0.0743^{*}$ \\
\hline & $(0.06)$ & $(0.11)$ & $(0.12)$ & $(0.03)$ & $(0.05)$ & $(0.04)$ \\
\hline \multirow[t]{2}{*}{ Net $\mathrm{RCA}_{j k}$} & $0.169 * * *$ & $0.383^{* * *}$ & $0.669 * * *$ & $0.0598^{* * *}$ & $0.368^{* * *}$ & $0.790^{* * *}$ \\
\hline & $(0.05)$ & $(0.09)$ & $(0.08)$ & $(0.02)$ & $(0.04)$ & $(0.04)$ \\
\hline \multirow[t]{2}{*}{ Time difference } & $0.0883^{* *}$ & -0.0486 & 0.00255 & 0.0215 & $-0.0912^{* * *}$ & $-0.0437^{* * *}$ \\
\hline & $(0.04)$ & $(0.04)$ & $(0.02)$ & $(0.02)(0.02)$ & $(0.02)$ & \\
\hline \multirow[t]{2}{*}{ Common language } & $0.814^{* *}$ & $0.892^{* * *}$ & $0.586^{* *}$ & $0.991^{* * *} *$ & $0.820^{* * *}$ & $0.762^{* * *}$ \\
\hline & $(0.34)$ & $(0.30)$ & $(0.30)$ & $(0.27)$ & $(0.21)$ & $(0.22)$ \\
\hline \multirow[t]{2}{*}{ Colonial relationship } & 0.452 & 0.0638 & $0.600^{* *}$ & $0.807^{* *}$ & $0.538^{* *}$ & $0.582^{* *}$ \\
\hline & $(0.38)$ & $(0.38)$ & $(0.29)$ & $(0.32)$ & $(0.23)$ & $(0.24)$ \\
\hline \multirow[t]{2}{*}{ Currency union } & -1.133 & $-1.395^{* * *}$ & -0.192 & $-1.386^{* * *}$ & $-0.637 * * *$ & $-0.699 * * *$ \\
\hline & $(0.79)$ & $(0.49)$ & $(0.28)$ & $(0.35)$ & $(0.21)$ & $(0.19))$ \\
\hline \multirow[t]{2}{*}{ Difference in latitude } & -0.00809 & $-0.0163^{* * *}$ & $-0.0144^{* * *}$ & -0.000589 & $-0.0144^{* * *}$ & $-0.0115^{* * *}$ \\
\hline & $(0.01)$ & $(0.01)$ & $(0.00)$ & $(0.00)$ & $(0.00)$ & $(0.00)$ \\
\hline \multirow[t]{2}{*}{ Common legal origin } & $1.082 * * *$ & $1.171^{* * *}$ & $1.063^{* * *}$ & $1.803^{* * *}$ & $1.956^{* * *}$ & $1.826^{* * *}$ \\
\hline & $(0.29)$ & $(0.24)$ & $(0.19)$ & $(0.20)$ & $(0.13)$ & $(0.13)$ \\
\hline \multirow[t]{2}{*}{ Common border } & $1.612^{* * *}$ & $1.222^{* * *}$ & $0.871^{* * *}$ & $1.895^{* * *}$ & $1.569 * * *$ & $1.591^{* * *}$ \\
\hline & $(0.43)$ & $(0.33)$ & $(0.28)$ & $(0.28)$ & $(0.19)$ & $(0.20)$ \\
\hline \multirow[t]{2}{*}{ Constant } & $-18.93^{* * *}$ & $-18.82^{* * *}$ & $-20.39 * * *$ & $-25.32^{* * *}$ & $-21.07^{* * *}$ & $-23.26^{* * *}$ \\
\hline & (1.97) & $(1.70)$ & $(1.71)$ & $(1.22)$ & $(0.86)$ & $(0.86)$ \\
\hline Observations & 6,806 & 6,806 & 6,806 & 115,702 & 115,702 & 115,702 \\
\hline N. of countries & 83 & 83 & 83 & 83 & 83 & 83 \\
\hline R-squared & 0.2494 & 0.2558 & 0.2868 & - & - & - \\
\hline Cluster error & acq-tgt & acq-tgt & acq-tgt & acq-tgt & acq-tgt & acq-tgt \\
\hline
\end{tabular}

Note: This table explores the relation between M\&A flows and trade flows using sector-level data. The dependent variable is dummy variable equals to one when the M\&A flow between two countries is positive, and zero otherwise. Total trade is measured as the sum of exports and imports. Relative comparative advantage (RCA) is based on Vollrath (1991). All regressions include gravity control variables that help explain levels of M\&A flows between each country pair based on the differences in latitude between countries, differences in time zones, whether they share a common language, whether they have a common legal origin, and whether the receiver (sender) country is (or was) a colony of the sender (receiver). The regressions also control for source- and target-country dummies. The sample includes 83 countries. Standard errors are clustered by country pairs. Sources: Calculations based on data from SDC Platinum and Comtrade.

openness) was associated with a higher probability of an M\&A transaction of 0.7 percent in the primary sector, 0.8 in the light manufacturing sector and 0.9 percent in the heavy manufacturing sector.

In all the three sectors, there is a positive relationship between the relative comparative advantage (RCA) of the receiver country and M\&As. Countries tend to invest in places with a comparative advantage in the sector they target, thereby securing their provision. This is true for all the sectors, as observed in 2016 and from 2000 to 2016. The evidence is different with respect to the net comparative advantage of the acquirer. Countries with a net comparative 
advantage in the primary sector tend to invest abroad, while countries with a comparative disadvantage tend to invest in the heavy manufacturing sector of foreign countries. There is no statistical evidence regarding light manufacturing.

At a few exceptions, gravity variables tend to have the expected sign and are statistically significant. Coefficients associated with common languages, colonial relationship, common legal origin, and common border are positive and most of the time statistically significant; coefficients associated with a difference in latitude are negative and statistically significant for the regression where the dependent variable is M\&A in the light and heavy manufacturing sectors. The time difference is negative and statistically significant for the light and heavy manufacturing sectors between 2000 and 2016. Otherwise, it is found to be not statistically significant. The negative sign associated with the currency union is unexpected and would require more research.

\subsection{ERGM estimations}

The regressions in Table 2 build on the first three columns of Table 1 by introducing a network element to the regression and using the ERGM estimation methodology. Results in the ERGM reproduces remarkably well the variables estimated with the logit, both in terms of sign and magnitude.

As for the logit results, even after controlling with gravity variables for common factors that can jointly drive trade and lending decisions, countries tend to invest more in partners with which they have larger trade flows. There is also no statistically significant relationship between the net RCA of source countries and M\&A flows, but countries are more likely to invest in countries with a positive net RCA in the heavy manufacturing sector. Results from gravity variables are generally less statistically significant in the ERGM regression when compared to the logit estimation.

The transitivity variable GWESP measures the influence of a third country in one country's decision to invest in another country. Precisely, it depicts the likeliness of a country to invest in a destination where one of its partners has already invested. This variable is positive and statistically significant for the three sectors, confirming the influence of the network effect on the decision to invest. The odds of an M\&A investment are 4.1 times higher in light manufacturing sector, 4.7 times higher in the primary sector, and 6.2 times higher in 
Table 2: Estimations of M\&A determinants using the Exponential Random Graph Model

\begin{tabular}{|c|c|c|c|}
\hline & \multicolumn{3}{|c|}{2016} \\
\hline & Primary & Light Manuf. & Heavy Manuf \\
\hline & $(1)$ & $(2)$ & $(3)$ \\
\hline \multirow[t]{2}{*}{ GWESP } & $1.54816^{* * *}$ & $1.42276^{* * *}$ & $1.82064^{* * *}$ \\
\hline & 0.1811 & 0.16098 & 0.17403 \\
\hline \multirow[t]{2}{*}{${\text { High } \text { Income }_{i}}$} & $0.52982^{*}$ & $0.67606^{*}$ & 0.30705 \\
\hline & 0.26591 & 0.27645 & 0.19755 \\
\hline \multirow[t]{2}{*}{ Trade Openness ${ }_{i}$} & $0.53991^{* * *}$ & $0.53595^{* * *}$ & $0.49849^{* * *}$ \\
\hline & 0.08548 & 0.08006 & 0.06181 \\
\hline \multirow[t]{2}{*}{ Net $\mathrm{RCA}_{i k}$} & $0.539^{*}$ & 0.04858 & -0.25272 \\
\hline & 0.21846 & 0.20151 & 0.17596 \\
\hline \multirow[t]{2}{*}{ Net $\mathrm{RCA}_{j k}$} & $0.52178^{* *}$ & -0.14125 & $0.50105^{* * *}$ \\
\hline & 0.20173 & 0.1801 & 0.13176 \\
\hline \multirow[t]{2}{*}{ Time difference } & 0.32651 & $-0.5492^{*}$ & $-0.34946^{*}$ \\
\hline & 0.38793 & 0.25096 & 0.16763 \\
\hline \multirow[t]{2}{*}{ Common language } & 0.34351 & 0.40806 & 0.11493 \\
\hline & 0.27177 & 0.28297 & 0.23589 \\
\hline \multirow[t]{2}{*}{ Colonial relationship } & 0.42955 & -0.0444 & 0.49192 \\
\hline & 0.33883 & 0.37301 & 0.26584 \\
\hline \multirow[t]{2}{*}{ Currency union } & -0.79079 & $-1.50295^{* *}$ & -0.17421 \\
\hline & 0.71188 & 0.57842 & 0.25978 \\
\hline \multirow[t]{2}{*}{ Difference in latitude } & 0.12954 & 0.85063 & 0.1356 \\
\hline & 0.89068 & 0.86323 & 0.5868 \\
\hline \multirow[t]{2}{*}{ Common legal origin } & $0.85866^{* * *}$ & $0.84151^{* * *}$ & $0.72245^{* * *}$ \\
\hline & 0.22756 & 0.20362 & 0.16275 \\
\hline \multirow[t]{2}{*}{ Common border } & $1.72408^{* * *}$ & $1.32523^{* * *}$ & $0.83294^{* *}$ \\
\hline & 0.3897 & 0.36213 & 0.29289 \\
\hline \multirow[t]{2}{*}{ Edges } & $-16.7497^{* * *}$ & -15.9279 *** & $-14.5744^{* * *}$ \\
\hline & 1.97473 & 1.87308 & 1.37028 \\
\hline Observations & 6,806 & 6,806 & 6,806 \\
\hline N. of countries & 83 & 83 & 83 \\
\hline Triangles & 80 & 147 & 940 \\
\hline AIC criteria & 684.6 & 915.3 & 1410 \\
\hline BIC criteria & 773.9 & 1005 & 1499 \\
\hline
\end{tabular}

Note: This table explores the relation between M\&A flows, trade flows, and network variable using sector-level data. The dependent variable is the M\&A flow between two countries. Total trade is measured as the sum of exports and imports. The GWESP indicator stands for geometrically weighted edgewise shared partner distribution and measures the likeliness of a common receiver country for two countries linked with an M\&A. Relative comparative advantage (RCA) is based on Vollrath (1991). All regressions include gravity control variables that help explain levels of M\&A flows between each country pair based on the differences in latitude between countries, differences in time zones, whether they share a common language, whether they have a common legal origin, and whether the receiver (sender) country is (or was) a colony of the sender (receiver). The sample includes 83 countries. Sources: Calculations based on data from SDC Platinum and Comtrade.

heavy manufacturing sector in the presence of a triangle. Annex A2 presents the goodness-of-fit statistics and horizontal parameter traces for each sectoral regression. The goodness-of-fit compares the parameters predicted by the model with the observed network. Both statistics are closed and the model appears to be a good fit for all the three sectors. Additionally, the trace of the simulated parameter values is relatively stable and these values vary around the mean over the course of the iteration. 
A number of tests is run to confirm the robustness of the estimations. First, the conclusions are are stable over the years, as it can be seen in Annex Table A4, A5, and A6, which displays the ERGM estimations for every year between 2000 and 2016 for the three sectors. Second, the conclusions hold when the dependant variable is replaced by a five year rolling cumulative MA (refer to Annex Table A7, A8, and A9). Finally, restricting the sample to transactions above 1 million US dollars does not impact the conclusions (refer to Annex Table A10, A11, and A12).

\subsection{TERGM estimations}

Computational limitations do not allow the use of all the gravity variables characterizing the relationship between dyads with the TERGM. Nevertheless, we decided to present the results of those regressions, acknowledging the limitation of their interpretation.

The regressions in Table 3 build on the last three columns of Table 1 by introducing a network element to the regression using the TERGM estimation. As in Table 1, the TERGM regression concludes that countries tend to invest more in partners with whom they have larger trade flows, for any sectors. The net RCA of recipient countries are statistically significant for the primary and heavy manufacturing sectors. The variable GWESP is positive and statistically significant in all three sectors, confirming the influence of the network effect on the decision to invest.

Annex A3 presents the goodness-of-fit statistics and horizontal parameter traces for each sectoral regression.

\section{Concluding remarks}

Building on bilateral estimates of M\&A determinants, the addition of a shared partner variable in a network estimate framework provides meaningful insights regarding the determinants of decisions about M\&A investments. From our results, we conclude that $M \& A$ decisions depend on trade openness and the traditional gravity variables. Moreover, an M\&A is more probable in a country 
Table 3: Estimations of M\&A determinants using the Temporal Exponential Random Graph Model

\begin{tabular}{lccc} 
& \multicolumn{3}{c}{$\mathbf{2 0 0 0 - 2 0 1 6}$} \\
\cline { 2 - 4 } & Primary & Light Manuf. & Heavy Manuf. \\
& $(1)$ & $(2)$ & $(3)$ \\
\hline GWESP & $1.5142^{* * *}$ & $1.28036^{* * *}$ & $1.59194^{* * *}$ \\
Trade openness & 0.1419 & 0.11597 & 0.1356 \\
& $0.6004^{* * *}$ & $0.45575^{* * *}$ & $0.26573^{* * *}$ \\
Net RCA of source country & 0.0815 & 0.06132 & 0.04348 \\
& $0.571^{* *}$ & 0.09198 & 0.23558 \\
Net RCA of receiver country & 0.208 & 0.16153 & 0.1394 \\
& $0.4607^{*}$ & 0.30831 & $0.64273^{* * *}$ \\
Edges & 0.1888 & 0.16364 & 0.12648 \\
& $-12.9352^{* * *}$ & $-10.63254^{* * *}$ & $-8.31684^{* * *}$ \\
Observations & 1.0514 & 0.77644 & 0.48243 \\
N. of countries & & & \\
Triangles & 115,702 & 115,702 & 115,702 \\
AIC criteria & 83 & 83 & 83 \\
BIC criteria & 3535 & 2347 & 18093 \\
\hline
\end{tabular}

Note: This table explores the relation between M\&A flows, trade flows, and network variables using sector-level data. The dependent variable is the M\&A flow between two countries. Total trade is measured as the sum of exports and imports. The GWESP indicator stands for geometrically weighted edgewise shared partner distribution and measures the likeliness of a common receiver country for two countries linked with an M\&A. Relative comparative advantage (RCA) is based on Vollrath (1991). The sample includes 83 countries. Sources: Calculations based on data from SDC Platinum and Comtrade.

displaying a positive net RCA. Finally, an investment is more likely if a partner of the country has already invested in the target location. 


\section{References}

Ahern, K. R., Daminelli, D. and Fracassi, C. (2015). Lost in translation? the effect of cultural values on mergers around the world. Journal of Financial Economics 117: 165-189.

Alfaro, L. and Charlton, A. (2009). Intra-industry foreign direct investment. The American Economic Review 99: 2096-2119.

Andrade, G., Mitchell, M. and Stafford, E. (2001). New evidence and perspectives on mergers. The Journal of Economic Perspectives 15: 103.

Antras, P. and Caballero, R. J. (2009). Trade and capital flows: A financial frictions perspective. Journal of Political Economy 117: 701-744.

Bergstrand, J. H. and Egger, P. (2007). A knowledge-and-physical-capital model of international trade flows, foreign direct investment, and multinational enterprises. Journal of International Economics 73: 278-308.

Blonigen, B. A., Davies, R. B., Waddell, G. R. and Naughton, H. T. (2007). Fdi in space: Spatial autoregressive relationships in foreign direct investment. European Economic Review 51: 1303-1325.

Chaney, T. (2014). The network structure of international trade. American Economic Review 104: 3600-3634.

Chari, A., Ouimet, P. P. and Tesar, L. L. (2009). The value of control in emerging markets. The Review of Financial Studies 23: 1741-1770.

Cranmer, S. J., Desmarais, B. A. and Menninga, E. J. (2012). Complex dependencies in the alliance network. Conflict Management and Peace Science 29: 279-313.

De Sousa, J. and Lochard, J. (2011). Does the single currency affect foreign direct investment? The Scandinavian Journal of Economics 113: 553-578.

Di Giovanni, J. (2005). What drives capital flows? the case of cross-border m\&a activity and financial deepening. Journal of international Economics 65: 127-149.

Ekholm, K., Forslid, R. and Markusen, J. R. (2007). Export-platform foreign direct investment. Journal of the European Economic Association 5: 776-795. 
Erdös, P. and Rényi, A. (1959). On random graphs, i. Publicationes Mathematicae (Debrecen) 6: 290-297.

Frank, O. and Strauss, D. (1986). Markov graphs. Journal of the american Statistical association 81: 832-842.

Goodreau, S. M., Kitts, J. A. and Morris, M. (2009). Birds of a feather, or friend of a friend? using exponential random graph models to investigate adolescent social networks. Demography 46: 103-125.

Greenaway, D. and Kneller, R. (2007). Firm heterogeneity, exporting and foreign direct investment. The Economic Journal 117.

Handcock, M. S., Robins, G., Snijders, T., Moody, J. and Besag, J. (2003). Assessing degeneracy in statistical models of social networks. Tech. rep., Citeseer.

Head, K. and Mayer, T. (2004). Market potential and the location of japanese investment in the european union. Review of Economics and Statistics 86: 959-972.

Head, K., Ries, J. and Swenson, D. (1995). Agglomeration benefits and location choice: Evidence from japanese manufacturing investments in the united states. Journal of international economics 38: 223-247.

Herman, P. R. (2017). Identifying multilateral dependencies in the world trade network. USITC Working Paper 73.

Hunter, D. R. (2007). Curved exponential family models for social networks. Social networks 29: 216-230.

Hunter, D. R. and Handcock, M. S. (2006). Inference in curved exponential family models for networks. Journal of Computational and Graphical Statistics 15: $565-583$.

Hunter, D. R., Handcock, M. S., Butts, C. T., Goodreau, S. M. and Morris, M. (2008). ergm: A package to fit, simulate and diagnose exponential-family models for networks. Journal of statistical software 24: nihpa54860.

Jackson, M. O. (2010). An overview of social networks and economic applications. The handbook of social economics 1: 511-85. 
Jarrell, G. A., Brickley, J. A. and Netter, J. M. (1988). The market for corporate control: The empirical evidence since 1980. The Journal of Economic Perspectives 2: 49-68.

Jensen, M. C. and Ruback, R. S. (1983). The market for corporate control: The scientific evidence. Journal of Financial economics 11: 5-50.

Jin, K. (2012). Industrial structure and capital flows. The American Economic Review 102: 2111-2146.

Ju, J. and Wei, S.-J. (2011). When is quality of financial system a source of comparative advantage? Journal of International Economics 84: 178-187.

Krivitsky, P. N. and Butts, C. T. (2013). Modeling valued networks with statnet. The Statnet Development Team : 2013.

Krivitsky, P. N. and Handcock, M. S. (2014). A separable model for dynamic networks. Journal of the Royal Statistical Society: Series B (Statistical Methodology) 76: 29-46.

Rajan, R. G. and Zingales, L. (1998). Financial dependence and growth. The American Economic Review 88: 559-586.

Romer, P. (1993). Idea gaps and object gaps in economic development. Journal of monetary economics 32: 543-573.

Snijders, T. A. (2002). Markov chain monte carlo estimation of exponential random graph models. Journal of Social Structure 3: 1-40.

Snijders, T. A., Pattison, P. E., Robins, G. L. and Handcock, M. S. (2006). New specifications for exponential random graph models. Sociological methodology 36: $99-153$.

Torre, A. De la, Didier, T., Ize, A., Lederman, D. and Schmukler, S. L. (2015). Latin america and the rising south: Changing world, changing priorities .

Vollrath, T. L. (1991). A theoretical evaluation of alternative trade intensity measures of revealed comparative advantage. Review of World Economics 127: $265-280$. 
Yeaple, S. R. (2003). The complex integration strategies of multinationals and cross country dependencies in the structure of foreign direct investment. Journal of International Economics 60: 293-314. 


\section{A1 Country Sample and Descriptive Statistics}

Table A1: Country sample

$\begin{array}{lllll}\text { Algeria } & \text { China } & \text { Guyana } & \text { Luxembourg } & \text { Slovak Rep. } \\ \text { Antigua \& Barbuda } & \text { Colombia } & \text { Hong Kong SAR } & \text { Malaysia } & \text { Slovenia } \\ \text { Argentina } & \text { Costa Rica } & \text { Hungary } & \text { Malta } & \text { South Africa } \\ \text { Australia } & \text { Croatia } & \text { Iceland } & \text { Mauritius } & \text { Spain } \\ \text { Austria } & \text { Cyprus } & \text { Iran } & \text { Mexico } & \text { St. Kit. \& Nev. } \\ \text { Azerbaijan } & \text { Czech Rep. } & \text { Iraq } & \text { Namibia } & \text { St. Lucia } \\ \text { Bahamas, The } & \text { Denmark } & \text { Ireland } & \text { Netherlands } & \text { Sweden } \\ \text { Barbados } & \text { Dominican Rep. } & \text { Israel } & \text { New Zealand } & \text { Switzerland } \\ \text { Belgium } & \text { Ecuador } & \text { Italy } & \text { Norway } & \text { Thailand } \\ \text { Belize } & \text { Estonia } & \text { Jamaica } & \text { Panama } & \text { Trin. \& Tob. } \\ \text { Bosnia \& Herzegovina } & \text { Fiji } & \text { Japan } & \text { Peru } & \text { Turkey } \\ \text { Botswana } & \text { Finland } & \text { Kazakhstan } & \text { Poland } & \text { UAE } \\ \text { Brazil } & \text { France } & \text { Korea } & \text { Portugal } & \text { United Kingdom } \\ \text { Brunei } & \text { Macedonia } & \text { Kuwait } & \text { Russia } & \text { United States } \\ \text { Bulgaria } & \text { Gabon } & \text { Latvia } & \text { Saudi Arabia } & \text { Uruguay } \\ \text { Canada } & \text { Germany } & \text { Lebanon } & \text { Seychelles } & \\ \text { Chile } & \text { Greece } & \text { Lithuania } & \text { Singapore }\end{array}$


Table A2: Descriptive statistics for 2016

\begin{tabular}{|c|c|c|c|c|c|}
\hline \multicolumn{6}{|c|}{ Primary } \\
\hline & Obs. & Mean & Std. Dev. & Min & Max \\
\hline Mergers and Acquisitions & 6,806 & 0.01 & 0.11 & 0 & 1 \\
\hline High income & 6,806 & 0.42 & 0.49 & 0 & 1 \\
\hline Trade openness (in logs) & 6,806 & 17.82 & 2.11 & 12.42 & 21.72 \\
\hline Net RCA of source country & 6,806 & -0.86 & 2.34 & -9.53 & 6.85 \\
\hline Net RCA of receiver country & 6,396 & -0.87 & 2.34 & -10.64 & 6.85 \\
\hline Time difference & 6,806 & 4.69 & 3.82 & 0 & 18 \\
\hline Common language & 6,806 & 0.07 & 0.26 & 0 & 1 \\
\hline Colonial relationship & 6,806 & 0.02 & 0.14 & 0 & 1 \\
\hline Currency union & 6,806 & 0.04 & 0.19 & 0 & 1 \\
\hline Difference in latitude & 6,806 & 30.26 & 23.60 & 0 & 105 \\
\hline Common legal origin & 6,806 & 0.06 & 0.24 & 0 & 1 \\
\hline Common border & 6,806 & 0.03 & 0.16 & 0 & 1 \\
\hline \multicolumn{6}{|c|}{ Light Manufacturing } \\
\hline & & Mean & Std. Dev. & Min & Max \\
\hline Mergers and Acquisitions & 6,806 & 0.02 & 0.14 & 0 & 1.00 \\
\hline High income & 6,806 & 0.42 & 0.49 & 0 & 1.00 \\
\hline Trade openness (in logs) & 6,806 & 17.82 & 2.11 & 12.42 & 21.72 \\
\hline Net RCA of source country & 6,806 & -0.52 & 1.13 & -7.04 & 1.66 \\
\hline Net RCA of receiver country & 6,396 & -0.52 & 1.13 & -7.04 & 1.91 \\
\hline Time difference & 6,806 & 4.69 & 3.82 & 0 & 18 \\
\hline Common language & 6,806 & 0.07 & 0.26 & 0 & 1 \\
\hline Colonial relationship & 6,806 & 0.02 & 0.14 & 0 & 1 \\
\hline Currency union & 6,806 & 0.04 & 0.19 & 0 & 1 \\
\hline Difference in latitude & 6,806 & 30.26 & 23.60 & 0 & 105 \\
\hline Common legal origin & 6,806 & 0.06 & 0.24 & 0 & 1 \\
\hline Common border & 6,806 & 0.03 & 0.16 & 0 & 1 \\
\hline \multicolumn{6}{|c|}{ Heavy Manufacturing } \\
\hline & Obs. & Mean & Std. Dev. & Min & $\operatorname{Max}$ \\
\hline Mergers and Acquisitions & 6,806 & 0.04 & 0.19 & 0 & 1.00 \\
\hline High income & 6,806 & 0.42 & 0.49 & 0 & 1.00 \\
\hline Trade openness (in logs) & 6,806 & 17.82 & 2.11 & 12.42 & 21.72 \\
\hline Net RCA of source country & 6,806 & -0.98 & 1.31 & -6.65 & 4.83 \\
\hline Net RCA of receiver country & 6,396 & -0.98 & 1.31 & -6.65 & 4.83 \\
\hline Time difference & 6,806 & 4.69 & 3.82 & 0 & 18 \\
\hline Common language & 6,806 & 0.07 & 0.26 & 0 & 1 \\
\hline Colonial relationship & 6,806 & 0.02 & 0.14 & 0 & 1 \\
\hline Currency union & 6,806 & 0.04 & 0.19 & 0 & 1 \\
\hline Difference in latitude & 6,806 & 30.26 & 23.60 & 0 & 105 \\
\hline Common legal origin & 6,806 & 0.06 & 0.24 & 0 & 1 \\
\hline Common border & 6,806 & 0.03 & 0.16 & 0 & 1 \\
\hline
\end{tabular}


Table A3: Descriptive statistics for 2000-2016

\begin{tabular}{lclccc}
\multicolumn{7}{c}{ Primary } & & & \\
\hline & Obs. & Mean & Std. Dev. & Min & Max \\
Mergers and Acquisitions & 115,702 & 0.02 & 0.13 & 0 & 1 \\
High income & 115,702 & 0.42 & 0.49 & 0 & 1 \\
Trade openness (in logs) & 115,702 & 12.26 & 3.80 & 4.85 & 21.82 \\
Net RCA of source country & 115,702 & -0.35 & 2.51 & -13.48 & 15.72 \\
Net RCA of receiver country & 115,702 & -0.35 & 2.51 & -13.48 & 15.72 \\
Time difference & 115,702 & 4.69 & 3.82 & 0 & 18 \\
Common language & 115,702 & 0.07 & 0.26 & 0 & 1 \\
Colonial relationship & 115,702 & 0.02 & 0.14 & 0 & 1 \\
Currency union & 115,702 & 0.04 & 0.19 & 0 & 1 \\
Difference in latitude & 115,702 & 30.26 & 23.59 & 0 & 105 \\
Common legal origin & 115,702 & 0.06 & 0.24 & 0 & 1 \\
Common border & 115,702 & 0.03 & 0.16 & 0 & 1 \\
& & & & & \\
\hline & Light Manufacturing & & & \\
Mergers and Acquisitions & 115,702 & 0.02 & 0.14 & 0 & 1 \\
High income & 115,702 & 0.42 & 0.49 & 0 & 1 \\
Trade openness (in logs) & 115,702 & 12.26 & 3.80 & 4.85 & 21.82 \\
Net RCA of source country & 115,702 & -0.51 & 1.40 & -11.28 & 3.59 \\
Net RCA of receiver country & 115,702 & -0.51 & 1.40 & -11.28 & 3.59 \\
Time difference & 115,702 & 4.69 & 3.82 & 0 & 18 \\
Common language & 115,702 & 0.07 & 0.26 & 0 & 1 \\
Colonial relationship & 115,702 & 0.02 & 0.14 & 0 & 1 \\
Currency union & 115,702 & 0.04 & 0.19 & 0 & 1 \\
Difference in latitude & 115,702 & 30.26 & 23.59 & 0 & 105 \\
Common legal origin & 115,702 & 0.06 & 0.24 & 0 & 1 \\
Common border & 115,702 & 0.03 & 0.16 & 0 & 1 \\
& & & & & \\
Heavy Manufacturing & & & \\
Mergers and Acquisitions & 115,702 & 0.04 & 0.19 & 0 & 1 \\
High income & 115,702 & 0.42 & 0.49 & 0 & 1 \\
Trade openness (in logs) & 115,702 & 12.26 & 3.80 & 4.85 & 21.82 \\
Net RCA of source country & 115,702 & -1.26 & 1.63 & -11.78 & 4.86 \\
Net RCA of receiver country & 115,702 & -1.26 & 1.63 & -11.78 & 4.86 \\
Time difference & 115,702 & 4.69 & 3.82 & 0 & 18 \\
Common language & 115,702 & 0.07 & 0.26 & 0 & 1 \\
Colonial relationship & 115,702 & 0.02 & 0.14 & 0 & 1 \\
Currency union & 115,702 & 0.04 & 0.19 & 0 & 1 \\
Difference in latitude & 115,702 & 30.26 & 23.59 & 0 & 105 \\
Common legal origin & 115,702 & 0.06 & 0.24 & 0 & 1 \\
& 115,702 & 0.03 & 0.16 & 0 & 1
\end{tabular}




\section{A2 Goodness of fit for ERGM results}

After running the ERGM, we estimate the goodness-of-fit and trace the MCMC plots of the statistically significant variables.

Figure A1: Primary sector
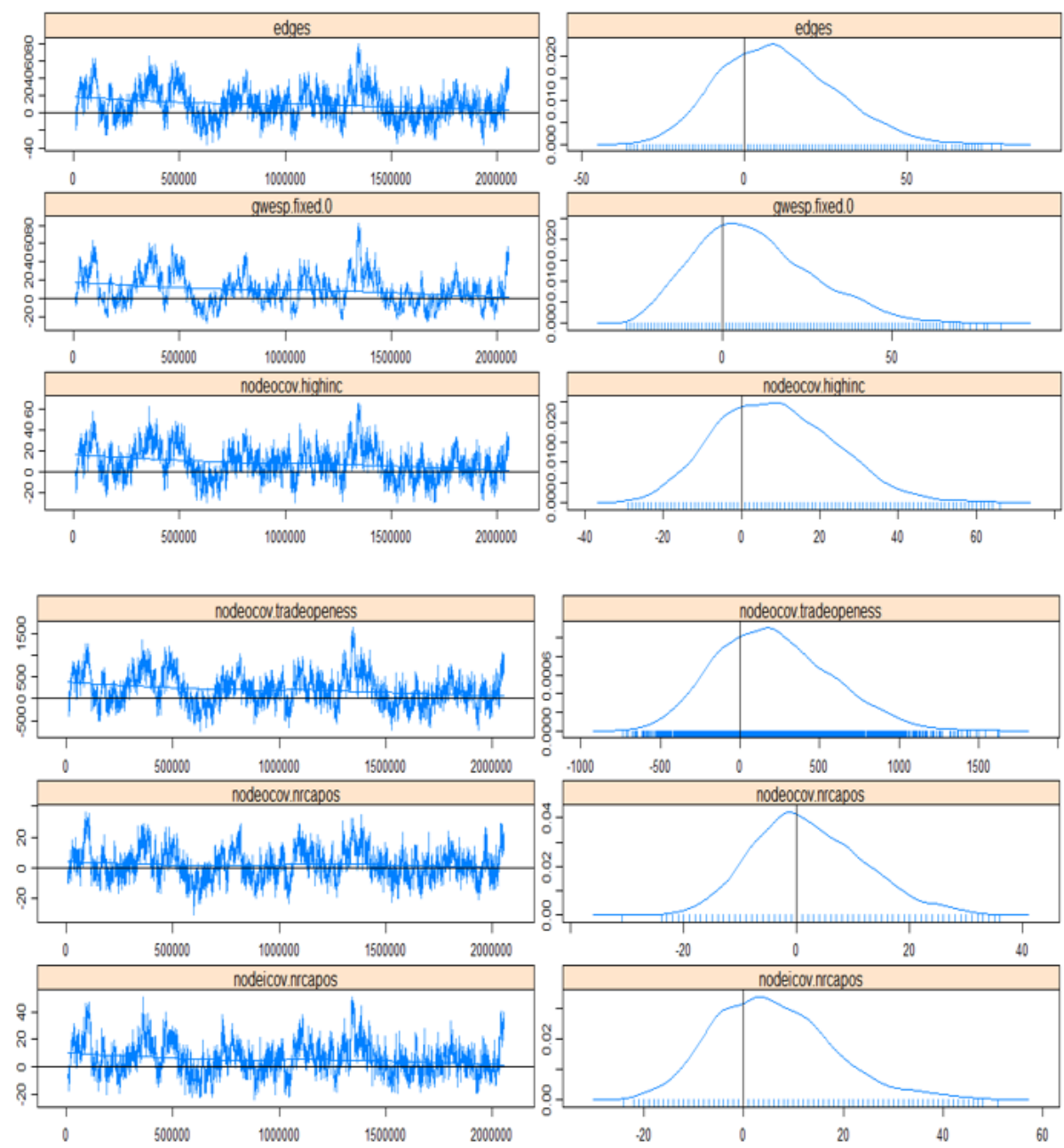
Figure A2: Light manufacturing
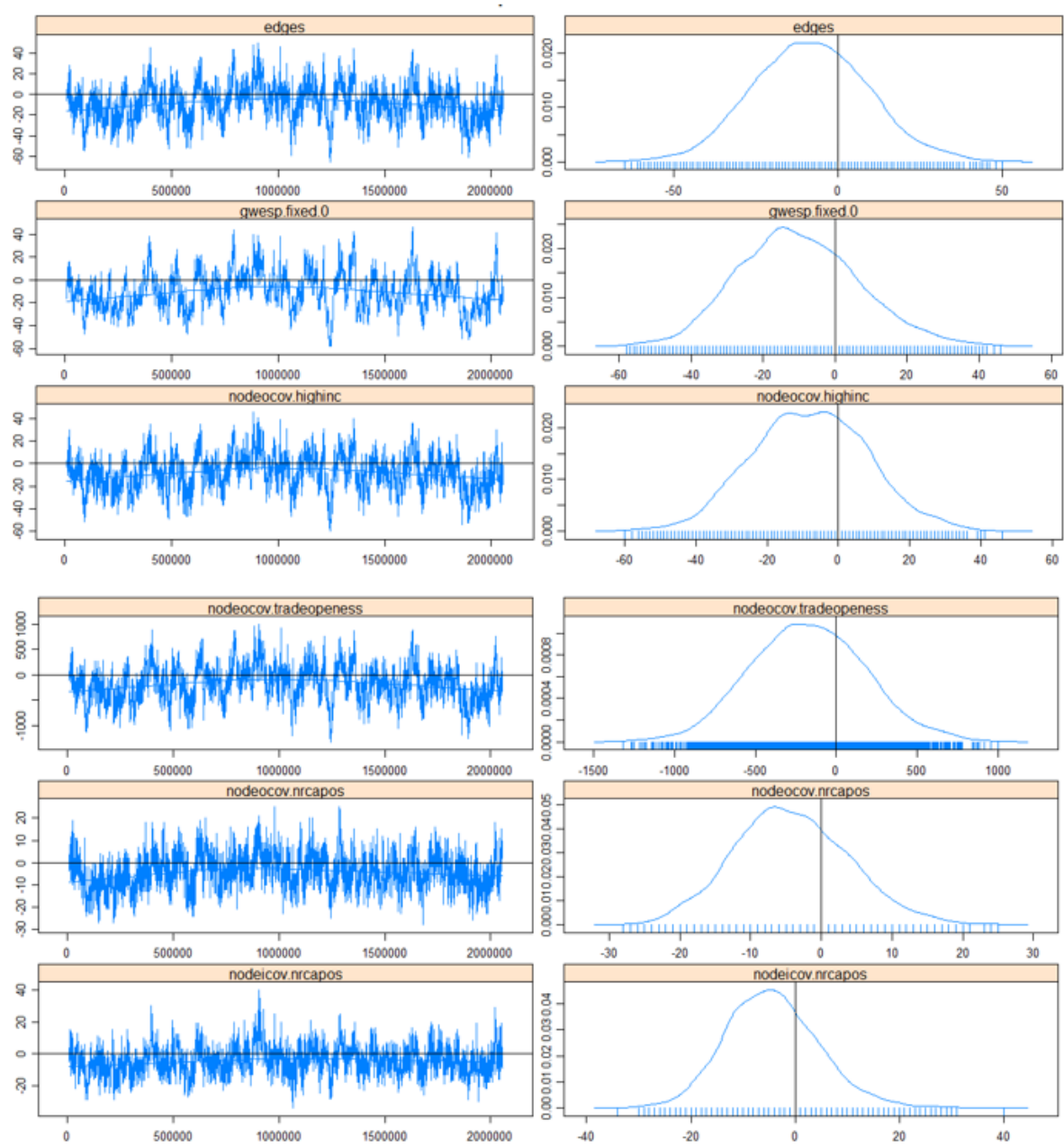
Figure A3: Heavy manufacturing
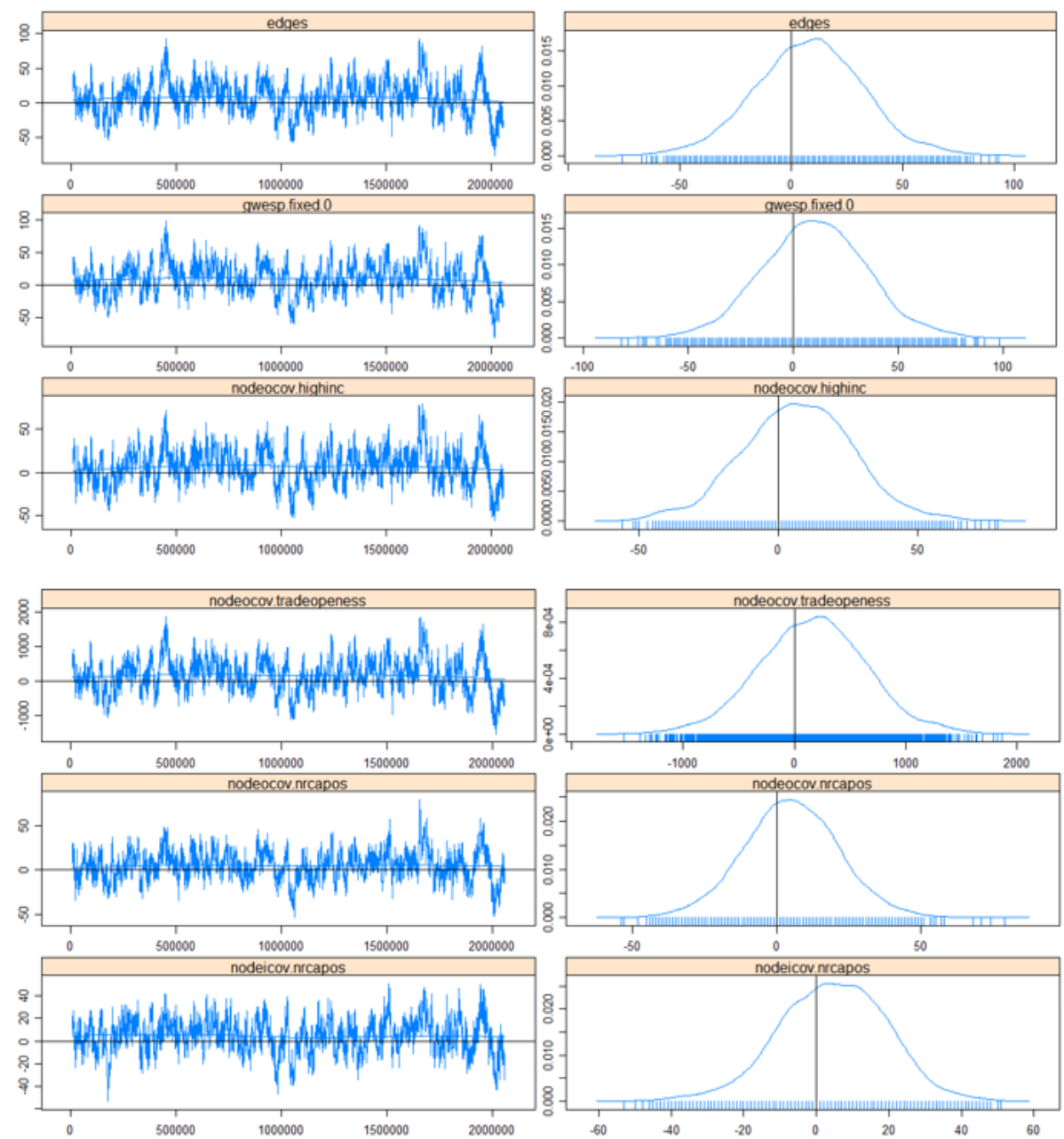

30 
Table A4: Estimation of M\&A in Primary sector determinants using ERGM procedure

\begin{tabular}{|c|c|c|c|c|c|c|c|c|c|c|c|c|c|c|c|c|c|}
\hline & $2000^{\circ}$ & 2001 & 2002 & 2003 & 2004 & 2005 & 2006 & 2007 & 2008 & 2009 & 2010 & 2011 & 2012 & $2013^{\circ}$ & 2014 & $2015^{\circ}$ & 2016 \\
\hline GWESP & 1.532 & $1.68^{* * *}$ & $2.1^{* * *}$ & $1.42^{* * *}$ & $1.97^{* * *}$ & $2.11^{* * *}$ & $2.13^{* * *}$ & $1.76^{* * *}$ & $2.01^{* * *}$ & $1.81^{* * *}$ & $1.88^{* * *}$ & $1.89^{* * *}$ & $1.73^{* * *}$ & 1.77 & $1.46^{* * *}$ & 1.91 & \\
\hline High Income & 1.531 & $1.05 *$ & $0.8 *$ & $0.9 * *$ & $0.56 *$ & $0.52 *$ & $0.62 * *$ & 0.7 *** & $0.63 * * *$ & $0.7 * * *$ & $0.65 * * *$ & $0.49 * *$ & $0.63 * *$ & 0.73 & $0.47 *$ & 0.69 & \\
\hline Trade Openness $i_{i}$ & 0.593 & $0.65 * * *$ & $0.56 * * *$ & $0.75 * * *$ & $0.82 * * *$ & $0.46 * * *$ & $0.44^{* * *}$ & $0.53 * * *$ & $0.35 * * *$ & $0.43 * *$ & $0.45^{* * *}$ & $0.46 * *$ & $0.5 * * *$ & 0.47 & $0.55 * * *$ & 0.34 & $0.54 * * *$ \\
\hline Net $\mathrm{RCA}_{i k}$ & 0.506 & $0.87 * *$ & $0.62 * *$ & $1.25 * * *$ & $1.35 * * *$ & 0.38 & 0.56 ** & $0.77 * * *$ & 0.39 * & 0.53 ** & $0.44 *$ & $0.47 * *$ & $0.5 *$ & 0.29 & 0.33 & 0.31 & $0.51 *$ \\
\hline Net $\mathrm{RCA}_{j k}$ & 0.824 & $0.78 * * *$ & $1 * * *$ & $0.87 * * *$ & 0.71 ** & 0.45 * & $0.39 *$ & $0.57 * * *$ & $0.54 * * *$ & $0.47 * *$ & $0.6 * * *$ & $0.55 * * *$ & $0.55 * * *$ & 0.77 & $0.62 * * *$ & 0.49 & $0.51 *$ \\
\hline Time difference & -0.644 & -0.5 & -0.28 & -0.27 & -0.36 & 0.14 & -0.08 & 0.04 & -0.28 & 0.03 & 0.63 & 0.59 & 0.02 & 0.69 & 0.23 & 0.9 & 0.32 \\
\hline Common language & 0.085 & 0.26 & -0.07 & 0.06 & -0.15 & 0.2 & 0.22 & -0.25 & 0.04 & -0.12 & -0.12 & $0.54 * *$ & 0.2 & 0.31 & 0.18 & 0.01 & 0.34 \\
\hline Colonial relationship & 0.054 & -0.11 & -0.3 & -0.21 & -0.55 & -0.04 & 0.2 & 0.09 & 0.54 & 0.56 * & 0.38 & 0.4 & 0.53 & 0.22 & $0.68 *$ & 0.65 & 0.49 \\
\hline Currency union & -0.23 & -0.11 & -0.32 & -0.63 & -1.24 & -0.66 & -0.63 & -1.1 & $-1.82 * *$ & $-2.33 *$ & -1.57 & -0.22 & -1.7 & -0.57 & -1.71 & -1.04 & -0.74 \\
\hline Difference in latitude & 14.914 & $-1.28 *$ & -0.39 & 0.14 & -1.02 & -1.02 & -0.15 & 1.08 & 0.31 & 0.22 & -0.18 & -0.54 & 0.37 & 15.75 & -0.47 & 15.7 & 0.19 \\
\hline Common legal origin & $\begin{array}{c}0.89 \\
0.89\end{array}$ & $1 * * *$ & $1.11 * * *$ & $0.9 * * *$ & $1.05 * * *$ & $0.92 * * *$ & $0.78^{* * *}$ & $0.83 * * *$ & $0.81 * * *$ & $0.79 * * *$ & $0.77 * * *$ & $0.41^{*}$ & $0.86^{* * * *}$ & 0.68 & $0.83 * * *$ & 0.6 & $0.83 * * *$ \\
\hline Common border & 0.871 & $1.17 * *$ & $1.07 *$ & $2.24 * * *$ & $1.11 *$ & 0.39 & $0.75 *$ & $1.7 * * *$ & $1.04 * * *$ & $1.36 * * *$ & $1.37 * * *$ & $0.94 * *$ & 0.69 & 1.47 & $1.49 * * *$ & 1.59 & $1.8^{* * *}$ \\
\hline Edges & -28.18 & $-12.72 * * *$ & $-12.81 * * *$ & $-15.54 * * *$ & $-15.38 * * *$ & $-10.6^{*} * *$ & $-11.11 * * *$ & $-13.68 * * *$ & $-10.21 * * *$ & $-11.26 * * *$ & $-11.72 * * *$ & $-11.38 * * *$ & $-12.3^{* * *}$ & -31.47 & $-15.92 * * *$ & $\begin{array}{l}1.03 \\
-28.98\end{array}$ & $\begin{array}{l}16.87 * * * \\
-16\end{array}$ \\
\hline Observations & 6,806 & 6,806 & 6,806 & 6,806 & 6,806 & 6,806 & 6,806 & 6,806 & 6,806 & 6,806 & 6,806 & 6,806 & 6,806 & 6,806 & 6,806 & 6,806 & 6,806 \\
\hline AIC criteria & 637.26 & 563.95 & 560.69 & 662.5 & 574.15 & 726.83 & 848.09 & 1009.74 & 1156.77 & 1034.64 & 1058.67 & 1138.24 & 959.88 & 876.42 & 883.95 & 788.86 & 685.05 \\
\hline BIC criteria & 726.62 & 653.3 & 650.05 & 751.86 & 663.5 & 816.19 & 937.45 & 1099.1 & 1246.13 & 1124 & 1148.02 & 1227.6 & 1049.23 & 965.77 & 973.31 & 878.21 & 774.41 \\
\hline Triangles & 76 & 74 & 90 & 86 & 147 & 154 & 207 & 340 & 451 & 309 & 408 & 409 & 241 & 191 & 136 & 136 & 80 \\
\hline
\end{tabular}

Note: This table explores the relation between M\&A flows, trade flows, and network variable. The dependent variable is the M\&A flow in primary sector between two countries. Total trade is measured as the sum of exports and imports. The GWESP indicator stands for geometrically weighted edgewise shared is based on Vollrath (1991). All regressions include gravity control variables that help explain levels of M\&A flows between each country pair based on the differences in latitude between countries, differences in time zones, whether they share a common language, whether they have a common legal origin, and whether the receiver (sender) country is (or was) a colony of the sender (receiver). • indicates the years for which the ERGM estimation did not convergence. Significance levels correspond to ${ }^{* * *} \mathrm{p}<0.001,{ }^{* *} \mathrm{p}<0.01,{ }^{*} \mathrm{p}<0.05$. Standard deviations are not reported. Sources: Calculations based on data from SDC Platinum and Comtrade. 
Table A5: Estimation of M\&A in Light Manufacturing determinants using ERGM procedure

\begin{tabular}{|c|c|c|c|c|c|c|c|c|c|c|c|c|c|c|c|c|c|}
\hline & 2000 & 2001 & 2002 & 2003 & 2004 & 2005 & 2006 & 2007 & 2008 & 2009 & 2010 & 2011 & 2012 & 2013 & 2014 & 2015 & 2016 \\
\hline GWESP & $1.535^{* * *}$ & $1.31^{* * *}$ & $1.24 * * *$ & $1.26^{* * *}$ & $1.44^{* * *}$ & $1.49^{* * *}$ & $1.35^{* * *}$ & $1.52^{* * *}$ & $1.51^{* * *}$ & $1.36^{* * *}$ & $1.31^{* * *}$ & $1.29 * * *$ & $1.35^{* * *}$ & $1.27^{* * *}$ & $1.37^{* * *}$ & $1.49 * * *$ & $1.42^{* * *}$ \\
\hline High Income $_{i}$ & $1.712 * * *$ & $1.16 * *$ & $0.63 *$ & 0.49 & $0.69^{*}$ & $0.9^{* *}$ & 0.43 & $0.71 * *$ & 0.27 & 0.38 & 0.23 & 0.37 & 0.79 ** & 0.3 & $0.65 *$ & 0.44 & $0.67 *$ \\
\hline Trade Openness ${ }_{i}$ & $0.408 * * *$ & $0.41 * * *$ & $0.54 * * *$ & $0.47 * * *$ & $0.46 * * *$ & $0.44 * * *$ & $0.53 * * *$ & $0.36 * * *$ & $0.47 * * *$ & $0.66 * * *$ & $0.53 * * *$ & $0.51 * * *$ & $0.5 * * *$ & $0.58 * * *$ & $0.62 * * *$ & $0.65 * * *$ & $0.54 * * *$ \\
\hline Net $\mathrm{RCA}_{i k}$ & -0.027 & -0.09 & 0.28 & 0.14 & 0.04 & -0.06 & -0.21 & 0.04 & 0.2 & 0.16 & -0.04 & 0.2 & 0.34 & 0.2 & 0.28 & 0.38 & 0.07 \\
\hline Net $\mathrm{RCA}_{j k}$ & 0.067 & 0.22 & 0.08 & 0.2 & 0.08 & $0.36 *$ & 0.3 . & -0.08 & -0.16 & -0.17 & -0.08 & 0.06 & -0.07 & $-0.38 *$ & -0.22 & 0.03 & -0.12 \\
\hline Time difference & $-0.686 * * *$ & $-0.71^{* * *}$ & $-0.55 *$ & -0.33 & $-0.46 *$ & -0.19 & -0.1 & $-0.46 *$ & -0.14 & -0.24 & -0.43 & -0.11 & -0.2 & -0.3 & -0.3 & 0 & $-0.51 *$ \\
\hline Common language & 0.185 & 0.07 & $0.5^{*}$ & 0.54 * & 0.38 & 0.02 & 0.13 & 0.21 & 0.48 . & 0.26 & 0.17 & $0.59 *$ & 0.68 ** & 0.49 . & 0.42 & 0.42 & 0.39 \\
\hline Colonial relationship & 0.779 * & 0.5 & 0.5 & 0.29 & 0.36 & 0.28 & 0.57 . & 0.19 & 0.12 & -0.12 & 0.22 & 0.22 & -0.2 & 0.08 & 0.24 & $0.8^{*}$ & 0.05 \\
\hline Currency union & -0.614 & $-1.02 * *$ & -0.66 . & -0.68 . & -0.54 & -0.44 & -0.46 & $-0.84 *$ & -0.38 & -0.9 * & $-1.71 * *$ & -0.78 & -0.48 & -0.53 & -0.74 & -0.1 & $-1.52 * *$ \\
\hline Difference in latitude & -0.658 & 1.58 & -0.54 & 0.12 & 1.21 & 1.16 & -0.18 & -0.3 & -0.07 & 0.62 & 0.38 & $-1.07 *$ & -0.62 & -0.12 & -0.15 & 0.43 & 0.83 \\
\hline Common legal origin & $1.181 * * *$ & $1.06^{* * *}$ & $0.99 * * *$ & $0.74 * * *$ & $0.67 * *$ & $0.97 * * *$ & $1.03 * * *$ & $1.23 * * *$ & $1^{* * *}$ & $1.18 * * *$ & $1.02 * * *$ & $1.06 * * *$ & $0.87 * * *$ & $1.12 * * *$ & $0.81 * * *$ & $0.95 * * *$ & $0.84 * * *$ \\
\hline Common border & $1.104^{* * *}$ & $1.19 * * *$ & $1.21 * * *$ & $1.37 * * *$ & $1.03 * *$ & $1.33^{* * *}$ & $1.41 * * *$ & 1.16 *** & $1.21 * * *$ & 1.06 ** & $1.5 * *$ & $1.22 * * *$ & $0.87 *$ & $1.16 * * *$ & $1.14 * *$ & $1.23 * * *$ & $1.33 * * *$ \\
\hline Edges & $-9.905 * * *$ & $-11.46 * * *$ & $-10.75 * * *$ & -10.51 *** & $-11.64 * * *$ & $-11.92 * * *$ & $-11.26 * * *$ & $-9.02 * * *$ & $-10.6 * * *$ & $-13.6 * * *$ & $-11.34 * * *$ & $-10.16 * * *$ & -10.79 *** & $-15.88 * * *$ & $-16.96 * * *$ & $-18.47 * * *$ & $-16.09 * * *$ \\
\hline Observations & 6,806 & 6,806 & 6,806 & 6,806 & 6,806 & 6,806 & 6,806 & 6,806 & 6,806 & 6,806 & 6,806 & 6,806 & 6,806 & 6,806 & 6,806 & 6,806 & 6,806 \\
\hline Triangles & 282 & 119 & 142 & 112 & 109 & 130 & 186 & 201 & 173 & 65 & 71 & 112 & 90 & 140 & 118 & 150 & 147 \\
\hline AIC criteria & 904.85 & 895.87 & 890.7 & 967.67 & 889.63 & 872.39 & 960.83 & 1022.39 & 948.14 & 723.01 & 845.25 & 981.85 & 931.11 & 941.09 & 858.57 & 838.86 & 917.5 \\
\hline BIC criteria & 994.2 & 985.23 & 980.06 & 1057.02 & 978.98 & 961.75 & 1050.19 & 1111.74 & 1037.49 & 812.36 & 934.6 & 1071.2 & 1020.47 & 1030.44 & 947.93 & 928.22 & 1006.86 \\
\hline
\end{tabular}

Note: This table explores the relation between M\&A flows, trade flows, and network variable. The dependent variable is the M\&A flow in light manufacturing
sector between two countries. Total trade is measured as the sum of exports and imports. The GWESP indicator stands for geometrically weighted edgewise shared partner distribution and measures the likeliness of a common receiver country for two countries linked with an M\&A. Relative comparative advantage (RCA) is based on Vollrath (1991). All regressions include gravity control variables that help explain levels of M\&A flows between each country pair based on the differences in latitude between countries, differences in time zones, whether they share a common language, whether they have a common legal origin, and whether the receiver (sender) country is (or was) a colony of the sender (receiver). Significance levels correspond to $* * * \mathrm{p}<0.001, * * \mathrm{p}<0.01, * \mathrm{p}<0.05$. Standard deviations are not reported. Sources: Calculations based on data from SDC Platinum and Comtrade. 
Table A6: Estimation of M\&A in Heavy Manufacturing determinants using ERGM procedure

\begin{tabular}{|c|c|c|c|c|c|c|c|c|c|c|c|c|c|c|c|c|c|}
\hline & 2000 & 2001 & 2002 & 2003 & 2004 & 2005 & 2006 & 2007 & 2008 & 2009 & 2010 & 2011 & 2012 & 2013 & 2014 & 2015 & 2016 \\
\hline GWESP & $1.982^{* * *}$ & $1.78^{* * *}$ & $2.24 * * *$ & $1.67^{* * *}$ & $1.57^{* * *}$ & $2.16 * * *$ & $1.77^{* * *}$ & $1.86^{* * * *}$ & $1.95 * * *$ & $1.88^{* * *}$ & $1.98^{* * *}$ & $1.94 * * *$ & $1.75^{* * * *}$ & $2.01 * * *$ & $2.11^{* * *}$ & $1.83^{* * *}$ & $1.83^{* * *}$ \\
\hline High Income $_{i}$ & 0.868 *** & $1.24 * * *$ & $0.65 * *$ & $0.7 * *$ & 0.75 ** & $0.39 *$ & $0.7^{* * *}$ & $0.69 * * *$ & $0.38 *$ & 0.65 ** & $0.73 * * *$ & $0.52 *$ & $0.59^{* *}$ & $0.71^{* * *}$ & $0.52 *$ & $0.47 *$ & \\
\hline Trade Openness ${ }_{i}$ & 0.536 *** & $0.55 * * *$ & $0.43 * * *$ & $0.57 * * *$ & $0.42 * * *$ & $0.47 * * *$ & $0.42 * * *$ & $0.48 * * *$ & $0.38 * * *$ & $0.4 * *$ & $0.38 * * *$ & $0.47 * * *$ & $0.42 * * *$ & $0.47 * * *$ & $0.45 * * *$ & $0.55^{* * *}$ & $0.49^{* * *}$ \\
\hline Net RCA $i k$ & -0.14 & -0.23 & $-0.35 *$ & -0.15 & 0.05 & 0.01 & -0.26 & -0.1 & 0.11 & -0.06 & -0.15 & -0.07 & -0.18 & -0.25 & 0 & -0.12 & -0.24 \\
\hline Net $\mathrm{RCA}_{j k}$ & $0.394 * *$ & $0.71 * * *$ & 0.48 ** & $0.7 * * *$ & $0.45 * *$ & $0.63 * * *$ & $0.6 * * *$ & $0.61 * * *$ & $0.51 * * *$ & $0.41 * *$ & $0.44 * * *$ & $0.63 * * *$ & $0.71 * * *$ & $0.46 * * *$ & $0.49 * * *$ & $0.66 * * *$ & $0.5 * * *$ \\
\hline Time difference & $-0.36 *$ & -0.33 & -0.02 & $-0.43 *$ & -0.05 & -0.23 & -0.29 & -0.13 & 0.19 & -0.16 & -0.12 & 0.03 & -0.11 & 0.2 & -0.03 & 0.07 & $-0.33 *$ \\
\hline Colonial relationship & $\begin{array}{c}-0.30 \\
0.315\end{array}$ & $0.68^{* *}$ & $\begin{array}{l}-0.02 \\
0.49 .\end{array}$ & $\begin{array}{l}-0.43 \\
0.45\end{array}$ & $\begin{array}{l}-0.03 \\
0.4\end{array}$ & $\begin{array}{l}-0.23 \\
-0.01\end{array}$ & $\begin{array}{l}-2.29 \\
0.38\end{array}$ & $\begin{array}{l}-0.13 \\
0.22\end{array}$ & $\begin{array}{l}0.19 \\
0.36\end{array}$ & $\begin{array}{l}-0.10 \\
0.18\end{array}$ & $\begin{array}{l}-0.12 \\
0.13\end{array}$ & $\begin{array}{c}0.03 \\
-0.02\end{array}$ & $\begin{array}{l}-0.11 \\
0.25\end{array}$ & $\begin{array}{l}0.2 \\
0.3\end{array}$ & $\begin{array}{l}-0.03 \\
0.39\end{array}$ & $\begin{array}{l}0.22 \\
0.22\end{array}$ & $\begin{array}{l}-0.53 * \\
0.53 *\end{array}$ \\
\hline Currency union & $-0.823 * *$ & -0.15 & -0.24 & $-1.09 * *$ & $-0.72 *$ & $-0.73 * *$ & $-1 * *$ & $-0.88 * *$ & -0.34 & $-0.9 * *$ & $-0.99 * *$ & $-0.68 *$ & $-0.93 * *$ & -0.3 & $-1.05 * *$ & & -0.2 \\
\hline $\begin{array}{l}\text { Durrency union } \\
\text { Difference in latitude }\end{array}$ & $\begin{array}{l}-0.823 \\
0.215\end{array}$ & $\begin{array}{l}-0.13 \\
0.37\end{array}$ & $\begin{array}{l}-0.24 \\
0.83\end{array}$ & $\begin{array}{c}-1.199 \\
0.49\end{array}$ & $\begin{array}{c}-0.72 * \\
0.58\end{array}$ & $\begin{array}{c}-0.13 \\
0.59\end{array}$ & $1.88 *$ & $\begin{array}{l}-0.88 \cdots \\
1.36\end{array}$ & $\begin{array}{l}-0.34 \\
0.21\end{array}$ & $\begin{array}{l}-0.9 \cdots \\
1.03\end{array}$ & $\begin{array}{l}-0.99 \\
0.49\end{array}$ & $\begin{array}{c}-0.68 \\
0.52\end{array}$ & $\begin{array}{l}-0.93 \\
0.76\end{array}$ & $\begin{array}{l}-0.3 \\
0.23\end{array}$ & $\begin{array}{c}-1.05 \\
0.05\end{array}$ & $\begin{array}{l}-0.03 \\
-0.08 \\
-0.08\end{array}$ & $\begin{array}{l}-0.22 \\
0.25\end{array}$ \\
\hline Common legal origin & $1.04 * * *$ & $0.75^{* * *}$ & $0.76^{* * *}$ & 1.03 *** & $0.76^{* * * *}$ & $1.07 * * *$ & $0.86 * * *$ & $0.96 * * *$ & $0.95 * * *$ & $0.81^{* * *}$ & $0.9 * * *$ & $0.97 * * *$ & $0.85 * * *$ & $0.85 * * *$ & $0.97 * * *$ & $0.86 * * *$ & $0.7 * * *$ \\
\hline Common language & -0.099 & -0.01 & -0.26 & 0.19 & 0.1 & 0.11 & -0.07 & 0.22 & 0.03 & 0.36 & 0.32 & 0.38 & 0.26 & -0.1 & 0.04 & 0.42 & 0.09 \\
\hline Common border & $1.323^{* * *}$ & $1.39^{* * * *}$ & $1.77 * * *$ & $1.21 * * *$ & $1.62 * * *$ & $1.52 * * *$ & $1.37 * * *$ & $1.31 * * *$ & $1.49 * * *$ & $1.33^{* * *}$ & $1.05^{* * *}$ & $1.2^{* * *}$ & $1.02 * * *$ & $1.15 * * *$ & $1.51^{* * *}$ & $0.94 * *$ & $0.82 * *$ \\
\hline Edges & $-11.831 * * *$ & $-12.39 * * *$ & $-11.52 * * *$ & $-12.37 * * *$ & $-10.85 * * *$ & $-11.81 * * *$ & $-11.95 * * *$ & $-12.5 * * *$ & $-10.47 * * *$ & $-11.21 * * *$ & $-10.61 * * *$ & $-11.96 * * *$ & $-11.23 * * *$ & $-15.07 * * *$ & $-14.51 * * *$ & $-16.18 * * *$ & $-14.57 * * *$ \\
\hline Observations & & 6,806 & 6,80 & 6,806 & 6,806 & 6,806 & $6,80 \mathrm{c}$ & 6,80 & 6,806 & 6,806 & 6,806 & 6,80 & 6,806 & 6,806 & 6,806 & 6,806 & 6,806 \\
\hline Triangles & 1269 & 1112 & 826 & 801 & 654 & 1026 & 1309 & 1726 & 143 & 769 & 921 & 11 & & 876 & 128 & 1122 & 940 \\
\hline AIC criteria & 1376.85 & 1326.86 & 1173.76 & 1197.49 & 1321.86 & 1282.44 & 1653.93 & 1734.35 & 1689.91 & 1369.9 & 1441.92 & 1460.81 & 1468. & 1352.7 & 1452.03 & 1387.89 & 1412.81 \\
\hline BIC criteria & 1466.21 & 1416.21 & 1263.11 & 1286.84 & 1411.22 & 1371.8 & 1743.28 & 1823.71 & 1779.26 & 1459.26 & 1531.28 & 1550.16 & 1558.13 & 1442.06 & 1541.39 & 1477.25 & 1502.17 \\
\hline
\end{tabular}

Note: This table explores the relation between M\&A flows, trade flows, and network variable. The dependent variable is the M\&A flow in heavy manufacturing sector between two countries. Total trade is measured as the sum of exports and imports. The GWESP indicator stands for geometrically weighted edgewise shared partner distribution and measures the likeliness of a common receiver country for two countries linked with an M\&A. Relative comparative advantage (RCA) is based on Vollrath (1991). All regressions include gravity control variables that help explain levels of M\&A flows between each country pair based on the differences in latitude between countries, differences in time zones, whether they share a common language, whether they have a common legal origin, Standard deviations are not reported. Sources: Calculations based on data from SDC Platinum and Comtrade. 
Table A7: Estimation of 5-year rolling M\&A in Primary sector determinants using ERGM procedure

\begin{tabular}{|c|c|c|c|c|c|c|c|c|c|c|c|c|c|c|c|c|c|}
\hline & 2000 & 2001 & 2002 & 2003 & 2004 & 2005 & 2006 & 2007 & 2008 & 2009 & 2010 & 2011 & 2012 & 2013 & 2014 & 2015 & 2016 \\
\hline GWESP & $1.465 * * *$ & $1.35^{* * *}$ & $1.63 * * *$ & $1.69^{* * *}$ & $1.53 * * *$ & $1.83 * * *$ & $1.93 * * *$ & $1.7^{* * *}$ & $1.87 * * *$ & $2.13 * * *$ & $2.08 * * *$ & $1.96 * * *$ & $2.16 * * *$ & $2.14 * * *$ & $1.97 * * *$ & $1.71 * * *$ & \\
\hline High Income $_{i}$ & $0.632 * * *$ & $0.73 * * *$ & $0.68 * * *$ & $0.65 * * *$ & $0.59 * * *$ & $0.48 * *$ & $0.48 * *$ & $0.61^{* * *}$ & $0.62 * * *$ & $0.63 * * *$ & $0.61^{* * *}$ & $0.56 * * *$ & $0.61 * * *$ & $0.62 * * *$ & $0.58 * * *$ & $0.46^{* * *}$ & $0.45 * * *$ \\
\hline Trade Openness ${ }_{i}$ & $0.519 * * *$ & $0.54 * * *$ & $0.47 * * *$ & $0.46 * *$ & $0.58 * * *$ & $0.47^{* * *}$ & $0.42 * * *$ & 0.5 *** & $0.41 * * *$ & $0.37 * * *$ & $0.35 * * *$ & $0.38^{* * *}$ & $0.34 * * *$ & 0.4 *** & $0.41 * * *$ & $0.37 * * *$ & $0.32 * * *$ \\
\hline Net $\mathrm{RCA}_{i k}$ & $0.35 *$ & $0.47 * *$ & 0.34 * & 0.34 * & $0.62 * * *$ & $0.42 * *$ & $0.42 * *$ & $0.62 * * *$ & $0.42 * *$ & $0.32 * *$ & $0.25 *$ & $0.24 *$ & 0.25 * & 0.39 ** & $0.32 * *$ & 0.21 & 0.1 \\
\hline Net $\mathrm{RCA}_{j k}$ & $0.619^{* * *}$ & $0.63^{* * *}$ & $0.65 * * *$ & $0.57 * * *$ & $0.65^{* * *}$ & $0.37^{* *}$ & $0.29 * *$ & $0.48 * * *$ & $0.38^{* * *}$ & $0.4 * * *$ & $0.45 * * *$ & 0.56 *** & $0.52 * * *$ & $0.5 * * *$ & $0.6^{* * *}$ & $0.73^{* * *}$ & $0.55 * * *$ \\
\hline Time difference & 0.105 & 0.01 & -0.17 & -0.25 & $-0.37 *$ & -0.15 & -0.11 & -0.19 & -0.07 & 0.02 & 0.06 & 0.18 & 0.24 & $0.4 *$ & $0.44 *$ & 0.33 & 0.23 \\
\hline Common language & 0.109 & 0.12 & 0.13 & 0.2 & 0.17 & 0.21 & 0.21 & 0.01 & 0.05 & 0.04 & 0.05 & 0.28 . & 0.27 . & 0.14 & 0.01 & 0.01 & 0.21 \\
\hline Colonial relationship & 0.363 & 0.36 & 0.18 & 0.18 & 0.08 & 0.41 & 0.41 & -0.04 & $0.49 *$ & $0.55 *$ & $0.51 *$ & $0.51 *$ & $0.48 *$ & $0.66 * * *$ & $0.73 * * *$ & $0.92 * * *$ & $0.8 * *$ \\
\hline Currency union & -0.279 & -0.24 & -0.32 & -0.58 & -0.45 & -0.58 & -0.6 . & $-0.77 *$ & $-1.21 * * *$ & $-1.3 * *$ & $-1.59 * * *$ & $-1.21 * *$ & $-0.96 * *$ & -0.72 & -0.54 & -0.41 & $-0.87 *$ \\
\hline Difference in latitude & 0.513 & -0.08 & -0.05 & -0.09 & 0.08 & 0.07 & 0.71 & 0.53 & 0.21 & 0.13 & 0.24 & 0.15 & 0.6 & 0.38 & -0.09 & 0.1 & 0.37 \\
\hline Common legal origin & $0.837 * * *$ & $0.87^{* * *}$ & $0.72 * * *$ & $0.7 * * *$ & $0.7 * * *$ & $0.67 * * *$ & $0.6 * * *$ & $0.72 * * *$ & $0.72 * * *$ & $0.7^{* * *}$ & $0.69^{* * *}$ & $0.65 * * *$ & $0.69 * * *$ & $0.72 * * *$ & $0.75 * * *$ & $0.87 * * *$ & $0.83 * * *$ \\
\hline Common border & $1.279 * * *$ & 1.39 *** & $1.24^{* * *}$ & $1.43 * * *$ & 1.25 *** & $1.21 * * *$ & $1.05 * * *$ & 1.36 *** & 1.21 *** & $1.32 * * *$ & $1.31 * * *$ & $1.29^{* * *}$ & $1.2 * * *$ & $1.19 * * *$ & $1.16 * * *$ & $1.1 * * *$ & $1.19 * * *$ \\
\hline Edges & $-12.026^{* * *}$ & $-11.71 * * *$ & $-10.79 * * *$ & $-10.72 * * *$ & $-12.19 * * *$ & $-11.03 * * *$ & $-11.12 * * *$ & $-12.01 * * *$ & $-10.58 * * *$ & $-10.19 * * *$ & $-10.18 * * *$ & $-10.47 * * *$ & $-10.67 * * *$ & $-14.13 * * *$ & $-13.73 * * *$ & $-12.78 * * *$ & $-11.99 * * *$ \\
\hline AIC & 1432.83 & 1424.8 & 1398.56 & 1422.22 & 1462.97 & 1527.32 & 1616.46 & 1810.72 & 1981.37 & 2022.81 & 2146.32 & 2276.36 & 2246.85 & 2106.68 & 2092.6 & 2011.78 & 1891.06 \\
\hline & 1522.49 & 1514.46 & 1488.23 & 1511.88 & 1552.63 & 1616.98 & 1706.12 & 1900.38 & 2071.03 & 2112.47 & 2235.98 & 2366.02 & 2336.51 & 2196.35 & 2182.26 & 2101.44 & 1980.72 \\
\hline Triangles & 640 & 579 & 558 & 570 & 694 & 848 & 932 & 1266 & 1570 & 1822 & 2104 & 2468 & 2482 & 2161 & 1950 & 1692 & 1459 \\
\hline
\end{tabular}

Note: This table explores the relation between M\&A flows, trade flows, and network variable. The dependent variable is equal to one if an M\&A flow occurred between two countries in the last 5 years in the primary sector. Total trade is measured as the sum of exports and imports. The GWESP indicator stands for geometrically weighted edgewise shared partner distribution and measures the likeliness of a common receiver country for two countries linked with an M\&A. Relative comparative advantage (RCA) is based on Vollrath (1991). All regressions include gravity control variables that help explain levels of M\&A flows between each country pair based on the differences in latitude between countries, differences in time zones, whether they share a common language, whether they have a common legal origin, and whether the receiver (sender) country is (or was) a colony of the sender (receiver). • indicates the years for which the
ERGM estimation did not convergence. Significance levels correspond to $* * * \mathrm{p}<0.001,{ }^{* *} \mathrm{p}<0.01,{ }^{*} \mathrm{p}<0.05$. Standard deviations are not reported. Sources: Calculations based on data from SDC Platinum and Comtrade. 
Table A8: Estimation of 5-year rolling M\&A in Light Manufacturing determinants using ERGM procedure

\begin{tabular}{|c|c|c|c|c|c|c|c|c|c|c|c|c|c|c|c|c|c|}
\hline & 2000 & 2001 & 2002 & 2003 & 2004 & 2005 & 2006 & 2007 & 2008 & 2009 & 2010 & 2011 & 2012 & 2013 & 2014 & 2015 & 2016 \\
\hline GWESP & $1.579^{* * *}$ & $1.59^{* * * *}$ & $1.93^{* * * *}$ & $1.61^{* * *}$ & $1.59^{* * *}$ & $1.44^{* * *}$ & $1.44^{* * * *}$ & $1.5^{* * *}$ & $1.44^{* * *}$ & $1.43^{* * * *}$ & 1.53 **** & $1.7 * * *$ & $1.88^{* * * *}$ & $1.84^{* * * *}$ & $1.63^{\text {**** }}$ & $1.49^{* * *}$ & $1.47^{* * *}$ \\
\hline High Income $_{i}$ & 1.018 *** & $1.18 * * *$ & $1.04 * * *$ & $1.06 * * *$ & $1.11^{* * *}$ & $0.96 * *$ & $0.98 * * *$ & $0.94 * *$ & $0.93 * * *$ & $0.85 * * *$ & $0.97 * *$ & $0.84 * *$ & $0.92 * * *$ & $1.08 * * *$ & $0.98 * * *$ & $0.76 * *$ & $0.7 * *$ \\
\hline Trade Openness $_{i}$ & 0.496 *** & $0.51^{* * *}$ & $0.46 * * *$ & $0.46 * * *$ & $0.42 * * *$ & $0.36 * * *$ & $0.33 * * *$ & $0.37 * * *$ & $0.4^{* * *}$ & $0.42^{* * * *}$ & $0.41 * * *$ & $0.38 * * *$ & $0.37 * * *$ & $0.6 * * *$ & $0.59 * * *$ & $0.63 * * *$ & $0.6 * * *$ \\
\hline Net RCA $i k$ & -0.062 & -0.13 & 0 & -0.01 & 0.08 & $0.31 *$ & 0.19 & 0.09 & 0.08 & 0.1 & 0.11 & $0.27 *$ & 0.16 & $-0.29 *$ & $-0.26 *$ & $\begin{array}{l}0.00 \\
-0.15\end{array}$ & ${ }_{-0.15}^{0.15}$ \\
\hline Net RCA & $0.49 * * *$ & $0.81 * * *$ & $0.63^{* * *}$ & $0.87 * * *$ & $0.93 * * *$ & $1.08 * * *$ & $0.88 * * *$ & $0.84 * * *$ & $0.88 * * *$ & $0.92 * * *$ & $0.97 * * *$ & $0.88 * * *$ & $1.01 * * *$ & $0.85 * * *$ & $0.79^{* * * *}$ & $0.99^{* * *}$ & $0.96 * * *$ \\
\hline Time difference & $-0.659 * * *$ & $-0.67 * * *$ & $-0.71 * * *$ & $-0.78 * * *$ & $-0.68 * * *$ & $-0.59 * * *$ & $-0.65 * * *$ & $-0.59 * * *$ & $-0.43 * * *$ & $-0.46 * * *$ & $-0.41 * * *$ & $-0.36 * *$ & $-0.26 *$ & $-0.31 *$ & $-0.29 *$ & -0.21 & $-0.37 * *$ \\
\hline Common 1 & -0.185 & -0.14 & -0.09 & -0.08 & 0.03 & 0.02 & -0.01 & 0 & -0.08 & -0.05 & 0.14 & 0.23 & $0.38 *$ & 0.14 & 0.08 & & 0.23 \\
\hline Colonia & $0.61 *$ & $0.65 * *$ & $0.58 *$ & $0.58^{* *}$ & 0.33 & 0.31 & 0.3 & 0.27 & 0.33 & 0.39 . & 0.3 & 0.2 & 0.2 & 0.28 & 0.35 & 0.33 & 0.39 \\
\hline Currency union & -0.449 . & -0.35 & -0.33 & -0.35 & -0.26 & -0.35 . & $-0.63 * *$ & $-0.78 * * *$ & $-0.53 *$ & $-0.56 * *$ & $-0.62 * *$ & $-0.62 * *$ & $-0.69 * *$ & $-0.53 *$ & -0.39 . & -0.27 & -0.18 \\
\hline Difference in latitude & -0.104 & 0.4 & 0.37 & -0.27 & -0.29 & -0.05 & -0.1 & 0.29 & 0.71 & 0.55 & 0.69 & 0.63 & $0.94 *$ & $0.96 *$ & $1.1^{* *}$ & $0.92 *$ & $0.87 *$ \\
\hline Common legal origin & $1.494 * * *$ & 1.49 *** & $1.41 * * *$ & $1.37 * * *$ & $1.3^{* * *}$ & $1.31 * * *$ & $1.32 * * *$ & 1.31 *** & $1.42^{* * * *}$ & $1.54 * * *$ & $1.4^{* * *}$ & $1.36 * * *$ & $1.35 * * *$ & $1.36 * * *$ & $1.37 * * *$ & $1.34 * * *$ & $1.36 * * *$ \\
\hline Common border & $1.205 * * *$ & $1.33 * * *$ & $1.41 * * *$ & $1.41 * * *$ & $1.31 * * *$ & $1.43 * * *$ & $1.31 * * *$ & $1.18^{* * *}$ & 1.18 *** & $1.26 * * *$ & $1.29 * * *$ & $1.23 * * *$ & $1.27 * * *$ & $1.37 * * *$ & $1.38 * * *$ & $1.21 * * *$ & $1.04 * * *$ \\
\hline Edges & $-10.015 * * *$ & $-10.8^{* * *}$ & $-10.48 * * *$ & $-9.66 * * *$ & $-9.36 * * *$ & $-8.91 * * *$ & $-8.39 * * *$ & $-9.2 * * *$ & $-10.03 * * *$ & $-9.95 * * *$ & $-10.19 * * *$ & $-10.09 * * *$ & $-10.64 * * *$ & $-17.73 * * *$ & $-17.38 * * *$ & $-17.74 * * *$ & $-16.77 * * *$ \\
\hline Observations & & 34,030 & & 34,03 & 34,030 & 34,03 & & 34,0 & 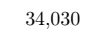 & 34,0 & 34,030 & 34,030 & 34,030 & 34,030 & 34,030 & 34,030 & 34,030 \\
\hline AIC & 2656. & 2658.24 & 2650.58 & 2734. & 2801.8 & 2788.21 & 3022.43 & 3249.59 & 3422.29 & 3362.98 & 3477.56 & 3383.67 & 3268.83 & 2916.63 & 2969.88 & 2883.37 & 2896.32 \\
\hline & 2746.34 & 2747.9 & 2740.24 & 2824.32 & 2891.46 & 2877.87 & 3112.09 & 3339.25 & 3511.95 & 3452.65 & 3567.22 & 3473.33 & 3358.5 & 3006.29 & 3059.54 & 2973.03 & 2985.98 \\
\hline Triangles & 5687 & 6069 & 6004 & 6363 & 6233 & 5738 & 6398 & 7540 & 8611 & 8854 & 9542 & 8674 & 8434 & 7485 & 7428 & 6949 & 6656 \\
\hline
\end{tabular}

Note: This table explores the relation between M\&A flows, trade flows, and network variable. The dependent variable is equal to one if an M\&A flow occurred between two countries in the last 5 years in the light manufacturing sector. Total trade is measured as the sum of exports and imports. The GWESP indicator stands for geometrically weighted edgewise shared partner distribution and measures the likeliness of a common receiver country for two countries linked with an M\&A. Relative comparative advantage (RCA) is based on Vollrath (1991). All regressions include gravity control variables that help explain levels of M\&A flows between each country pair based on the differences in latitude between countries, differences in time zones, whether they share a common language, whether they have a common legal origin, and whether the receiver (sender) country is (or was) a colony of the sender (receiver). Significance levels correspond to ${ }^{* *} \mathrm{p}<0.001,{ }^{* *} \mathrm{p}<0.01,{ }^{*} \mathrm{p}<0.05$. Standard deviations are not reported. Sources: Calculations based on data from SDC Platinum and Comtrade. 
Table A9: Estimation of 5-year rolling M\&A in Heavy Manufacturing determinants using ERGM procedure

\begin{tabular}{|c|c|c|c|c|c|c|c|c|c|c|c|c|c|c|c|c|c|}
\hline & 2000 & 2001 & 2002 & 2003 & 2004 & 2005 & 2006 & 2007 & 2008 & 2009 & 2010 & 2011 & 2012 & 2013 & 2014 & 2015 & $\begin{array}{ll}2016 \\
151 * * *\end{array}$ \\
\hline GWESP & $1.72^{* * *}$ & $1.86 * * *$ & $1.87^{* * * *}$ & $1.68^{* * *}$ & $1.69^{* * *}$ & $1.64 * * *$ & 1.76 *** & $1.62 * * *$ & $1.86^{* * *}$ & $1.71^{* * *}$ & $1.59^{* * *}$ & $1.75^{* * *}$ & $1.83^{* * *}$ & $1.84^{* * *}$ & $1.9^{* * *}$ & $1.62^{* * * *}$ & $1.54 * * *$ \\
\hline High Income $_{i}$ & $0.829 * * *$ & 0.88 *** & $0.8 * * *$ & $0.73^{* * *}$ & $0.73 * * *$ & $0.63^{* * *}$ & $0.52 * * *$ & 0.56 * & $0.5 * * *$ & $0.42 * *$ & $0.35 * *$ & $0.35 * *$ & 0.43 & $0.47 * * *$ & $0.45 * * *$ & & $3 * *$ \\
\hline ness $_{i}$ & 0.376 *** & $0.34 * * *$ & $0.34 * * *$ & $0.38^{* * *}$ & $0.38^{* * *}$ & $0.37 * * *$ & $0.38^{* * *}$ & $0.39 * * *$ & 0.36 *** & 0.39 *** & $0.4^{* * *}$ & $0.38 * * *$ & 0.41 *** & $0.46 * * *$ & $0.43 * * *$ & $0.47 * * *$ & $0.47 * * *$ \\
\hline $\mathrm{RC}$ & -0.152 & -0.25 * & -0.05 & 0.05 & 0.07 & 0.01 & 0.02 & 0.06 & 0 & -0.05 & -0.03 & 0.04 & 0.15 & 0.14 & 0.18 & 0.12 & 0.16 \\
\hline $\mathrm{RCA}_{j k}$ & $0.353 * *$ & $0.28 * *$ & 0.21 & 0.14 & 0.12 & 0.17 & 0.11 & 0.07 & 0.01 & 0 & -0.03 & 0.05 & 0.02 & $-0.21 *$ & -0.16 & & -0.17 \\
\hline Time difference & $-0.529 * * *$ & $-0.64 * * *$ & $-0.65 * * *$ & $-0.73 * * *$ & $-0.68 * * *$ & $-0.54 * * *$ & $-0.43 * *$ & $-0.42 * *$ & -0.39 ** & $-0.32 *$ & $-0.48 * * *$ & $-0.45 * *$ & -0.27 . & $-0.29 *$ & $-0.28 *$ & -0.19 & $-0.31 *$ \\
\hline Common language & 0.219 & 0.08 & 0.26 & 0.26 & 0.2 & 0.14 & 0.21 & & 0.23 & 0.33 & 0.34 & $0.41 *$ & $0.37 *$ & $0.45^{* *}$ & 0.35 & $0.47^{* *}$ & $0.53 * *$ \\
\hline Colonial relationship & 0.485 & $0.57^{*}$ & $0.55 *$ & 0.42 & 0.38 & 0.42 . & $0.5 *$ & 0.29 & 0.45 * & 0.3 & 0.38 . & 0.2 & 0.09 & 0.1 & 0.2 & 0.15 & 0.25 \\
\hline Currency union & $-0.609 *$ & $-0.78^{* * *}$ & -0.69 ** & $-0.71^{* *}$ & $-0.45 *$ & -0.36 & -0.15 & -0.14 & -0.12 & -0.18 & -0.35 & -0.34 & -0.45 . & $-0.67 *$ & $-0.57 *$ & -0.25 & -0.24 \\
\hline Difference in & -0.352 & -0.39 & -0.42 & -0.42 & -0.11 & 0.21 & 0.02 & 0.12 & 0.15 & 0 & -0.23 & -0.34 & 0.26 & 0.49 & 0.39 & 0.31 & 0.64 \\
\hline Common & $1.059 * * *$ & $1.11^{* * *}$ & $1.09 * * *$ & $1.07 * * *$ & & $0.99^{* * *}$ & $0.98 * * *$ & $1.04 * * *$ & $1.12 * * *$ & $1.14^{* * *}$ & $1.12 * * *$ & & & & & $1.06 * * *$ & $1.06 * * *$ \\
\hline Common border & $1.567 * * *$ & $1.37^{* * *}$ & $1.33^{* * *}$ & $1.36 * * *$ & $1.42 * * *$ & $1.32^{* * *}$ & $1.3^{* * *}$ & $1.46^{* * *}$ & $1.39 * * *$ & $1.42 * * *$ & $1.24 * * *$ & $1.19^{* * *}$ & 1.29 & 1.37 & $1.38 * * *$ & $1.56 * * *$ & $1.47 *$ \\
\hline Edges & $-8.808 * * *$ & $-8.34 * * *$ & $-8.32 * * *$ & -8.56 *** & $-9.03 * * *$ & $-9.14 * * *$ & $-9.28 * * *$ & $-9.42 * * *$ & $-9.33 * * *$ & $-9.24 * * *$ & $-8.91 * * *$ & $-8.83 * * *$ & $-10.09 * * *$ & $-14.13 * * *$ & $-13.64 * * *$ & $-14.05 * * *$ & $-14.22 * * *$ \\
\hline Observations & & & & 34,030 & 34,030 & & & & 34,030 & & 34,030 & 34 , & & 34,030 & & 34,030 & 34,030 \\
\hline AIC & 2027.16 & 2073.53 & 2076.36 & 2080 & 2015.78 & 2025.49 & 2060.16 & 2156.11 & 2097.39 & 2046.38 & 2114.56 & 2151.08 & 2105.1 & 2054 & 2076.22 & 2099.3 & 2091.99 \\
\hline & 2116.82 & 2163.19 & 2166.02 & 2169.67 & 2105.44 & 2115.15 & 2149.82 & 2245.77 & 2187.05 & 2136.04 & 2204.22 & 2240.74 & 2194.76 & 2143.66 & 2165.88 & 2188.96 & 2181.65 \\
\hline Triangles & 2127 & 2205 & 2063 & 1853 & 1607 & 1529 & 1771 & 1875 & 1987 & 1758 & 1795 & 1939 & 1905 & 1882 & 1928 & 1947 & 1763 \\
\hline
\end{tabular}

Note: This table explores the relation between M\&A flows, trade flows, and network variable. The dependent variable is equal to one if an M\&A flow occurred between two countries in the last 5 years in the heavy manufacturing sector. Total trade is measured as the sum of exports and imports. The GWESP indicator stands for geometrically weighted edgewise shared partner distribution and measures the likeliness of a common receiver country for two countries linked with an M\&A. Relative comparative advantage (RCA) is based on Vollrath (1991). All regressions include gravity control variables that help explain levels of M\&A flows between each country pair based on the differences in latitude between countries, differences in time zones, whether they share a common language, whether they have a common legal origin, and whether the receiver (sender) country is (or was) a colony of the sender (receiver). Significance Comtrade. 
Table A10: Estimation of 5-year rolling M\&A superior to 1 million US dollars in Primary sector determinants using ERGM procedure

\begin{tabular}{|c|c|c|c|c|c|c|c|c|c|c|c|c|c|c|c|c|c|}
\hline & 2000 & 2001 & 2002 & 2003 & 2004 & 2005 & 2006 & 2007 & 2008 & 2009 & 2010 & 2011 & 2012 & 2013 & 2014 & 2015 & 2016 \\
\hline GWESP & $1.611^{* * *}$ & $1.49^{* * *}$ & $1.69^{* * *}$ & $1.64^{* * *}$ & $1.51^{* * *}$ & $1.7 * * *$ & $1.82^{* * *}$ & $1.59^{* * *}$ & $1.83^{* * *}$ & $2.06^{* * *}$ & $2.06^{* * *}$ & $1.95^{* * *}$ & $2.07^{* * *}$ & $2.04^{* * *}$ & $2.03^{* * *}$ & $1.8^{* * *}$ & $1.81^{* * *}$ \\
\hline High Income $_{i}$ & $0.681 * * *$ & $0.74 * * *$ & $0.67 * * *$ & $0.61 * *$ & $0.52 * *$ & $0.37 *$ & $0.44 * *$ & $0.52 * * *$ & 0.58 *** & $0.65 * * *$ & $0.58 * * *$ & $0.61 * * *$ & $0.57 * * *$ & $0.64 * * *$ & $0.53 * * *$ & $0.43 * *$ & $0.42 * *$ \\
\hline Trade Openness ${ }_{i}$ & $0.517 * * *$ & $0.53^{* * *}$ & $0.46 * * *$ & $0.5 * *$ & $0.59 * * *$ & $0.51 * * *$ & $0.44^{* * *}$ & $0.51 * * *$ & $0.42 * * *$ & 0.39 *** & $0.35 * * *$ & $0.4^{* * *}$ & $0.35 * * *$ & $0.41^{* * *}$ & $0.38^{* * *}$ & $0.36 * * *$ & $0.31 * * *$ \\
\hline Net RCA ${ }_{i k}$ & 0.376 ** & $0.45 * *$ & $0.36 *$ & $0.4^{* *}$ & 0.63 *** & $0.47 * * *$ & $0.47 * * *$ & $0.58 * * *$ & $0.42 * *$ & $0.39 * *$ & 0.21 & 0.23 & 0.17 & $0.37 * *$ & $0.28 *$ & 0.2 & 0.04 \\
\hline Net RCA $\mathrm{R}_{j k}$ & $0.598 * * *$ & $0.61 * * *$ & $0.65 * * *$ & $0.58 * * *$ & $0.65 * * *$ & $0.41 * * *$ & $0.35 * *$ & $0.5 * * *$ & $0.39^{* * *}$ & $0.43^{* * *}$ & $0.49^{* * *}$ & $0.57^{* * *}$ & $0.53 * * *$ & $0.51^{* * *}$ & $0.59^{* * *}$ & $0.7 * * *$ & $0.57^{* * *}$ \\
\hline Time difference & 0.133 & 0.08 & -0.13 & -0.29 & $-0.41 *$ & -0.18 & -0.2 & -0.13 & -0.06 & 0.13 & 0.12 & 0.31 & 0.28 & $0.45 *$ & $0.44 *$ & 0.37 & 0.26 \\
\hline Common language & 0.136 & 0.11 & 0.07 & 0.21 & 0.24 & 0.2 & 0.07 & -0.04 & 0.02 & -0.02 & -0.02 & 0.12 & 0.15 & 0.01 & 0.06 & -0.02 & 0.15 \\
\hline Colonial relationship & & & & & & $0.54 *$ & $0.5 *$ & -0.02 & $0.54 *$ & $0.52 *$ & $0.58 *$ & $0.48 *$ & $0.45 *$ & $0.52 *$ & $0.74 * *$ & $0.87 * * *$ & $0.68 * *$ \\
\hline Currency & & & & & & & $\begin{array}{l}-0.52 \\
-0.52 \\
-\end{array}$ & $-0.71 *$ & $-1.07 * *$ & $-1.26 * * *$ & $-1.43 * *$ & $-1.18 * *$ & $\begin{array}{l}-0.99 \\
-0.99\end{array}$ & $\begin{array}{l}0.02 \\
-0.71 .\end{array}$ & & -0.45 & $-0.84 *$ \\
\hline $\begin{array}{l}\text { Differes } \\
\text { Difles }\end{array}$ & & & & & & & & $\begin{array}{l}-0.11 \\
0.47\end{array}$ & $\begin{array}{l}-1.016 \\
0.26\end{array}$ & 0.07 & $\begin{array}{c}-1.45 \\
0.29\end{array}$ & $\begin{array}{l}-1.10 \\
0.16\end{array}$ & 0.54 & & & 0.0 & 0.24 \\
\hline Common le & $0.819^{* * *}$ & $0.88^{*}$ & 0.68 * & $0.62 * * *$ & 0.67 & 0.64 * & $0.59^{* * *}$ & $0.75 * * *$ & $0.69^{* * *}$ & $0.71^{* * *}$ & $0.71^{* * *}$ & $0.72 * * *$ & $0.78^{* * *}$ & $0.75^{* * *}$ & $0.75^{* * *}$ & $0.87^{* * *}$ & $0.87^{* * *}$ \\
\hline Commor & $1.352 * * *$ & $1.45^{* * *}$ & $1.2 *$ & 1.4 & $1.35 * * *$ & $1.15^{* * *}$ & $1.04 * * *$ & $1.45 * * *$ & 1.16 *** & $1.43 * * *$ & 1.38 *** & & $1.3 * * *$ & $1.26 * * *$ & $1.21^{* * *}$ & $1.23 * * *$ & $1.22 * * *$ \\
\hline Edges & $-12.248 * * *$ & $-11.57 * * *$ & $-10.65 * * *$ & $-11.15 * * *$ & $-12.3 * * *$ & $-11.54 * * *$ & $-11.24 * * *$ & $-12 * * *$ & $-10.81 * * *$ & $-10.52 * * *$ & $-10.25 * * *$ & $-10.83 * * *$ & $-10.58 * * *$ & $-14.35 * * *$ & $-13.32 * * *$ & $-12.64 * * *$ & $-11.63 * * *$ \\
\hline servatiol & & & & & & & & & & & & & & & & & 34,030 \\
\hline & & & & & & & & & & & & & & & & & 1831.43 \\
\hline BIC & 1423.74 & $\begin{array}{l}1425.42 \\
\end{array}$ & $\begin{array}{l}1392.29 \\
\end{array}$ & 1426.93 & 1447.77 & 1546.39 & $\begin{array}{l}1625.22 \\
-105\end{array}$ & 1837.22 & 1985.19 & 2024.45 & 2138.77 & 2247.59 & 2243.41 & 2122.36 & 2098.85 & 2013.07 & $\begin{array}{l}1921.09 \\
\end{array}$ \\
\hline Triangles & 575 & 532 & 494 & 510 & 553 & 695 & 781 & 1145 & 1452 & 1681 & 1970 & 2267 & 2295 & 1996 & 1820 & 1571 & 1350 \\
\hline
\end{tabular}

494

1681

Ste relation between M\&A flows, trade flows, and network variable. The dependent variable is equal to one if an M\&A transaction superior to 1 million US dollars occurred between two countries in the last 5 years in the primary sector. Total trade is measured as the sum of exports country for two countries linked with an M\&A. Relative comparative advantage (RCA) is based on Vollrath (1991). All regressions include gravity control variables that help explain levels of M\&A flows between each country pair based on the differences in latitude between countries, differences in time zones, whether they share a common language, whether they have a common legal origin, and whether the receiver (sender) country is (or was) a colony of the sender (receiver). • indicates the years for which the ERGM estimation did not convergence. Significance levels correspond to ${ }^{* * *} \mathrm{p}<0.001,{ }^{* *} \mathrm{p}<0.01,{ }^{*} \mathrm{p}<0.05$. Standard deviations are not reported. Sources: Calculations based on data from SDC Platinum and Comtrade. 
Table A11: Estimation of 5-year rolling M\&A superior to 1 million US dollars in Light Manufacturing determinants using ERGM procedure

\begin{tabular}{|c|c|c|c|c|c|c|c|c|c|c|c|c|c|c|c|c|c|}
\hline & 2000 & 2001 & 2002 & 2003 & 2004 & 2005 & 2006 & 2007 & 2008 & 2009 & 2010 & 2011 & 2012 & 2013 & 2014 & 2015 & 2016 \\
\hline GWESP & $1.724^{* * *}$ & $1.88^{* * *}$ & $1.92^{* * *}$ & $1.62^{* * *}$ & $1.58^{* * *}$ & $1.63^{* * *}$ & $1.79^{* * *}$ & $1.64^{* * *}$ & $1.84^{* * *}$ & $1.71^{* * *}$ & $1.6^{* * *}$ & $1.82^{* * *}$ & $1.86^{* * *}$ & $1.84^{* * *}$ & $1.84^{* * *}$ & $1.67^{* * *}$ & $1.54^{* * *}$ \\
\hline High Income $_{i}$ & $0.813 * * *$ & $0.87 * * *$ & $0.82 * * *$ & $0.78^{* * *}$ & $0.8 * * *$ & $0.74 * * *$ & $0.54 * * *$ & $0.64 * * *$ & $0.55 * * *$ & $0.5 * * *$ & $0.37 * *$ & $0.35 * *$ & $0.44 * * *$ & $0.48^{* * *}$ & $0.46 * * *$ & $0.51^{* * *}$ & $0.53^{* * *}$ \\
\hline Trade Openness ${ }_{i}$ & $0.376 * * *$ & $0.34 * * *$ & $0.34 * * *$ & $0.39^{* * *}$ & $0.4^{* * *}$ & $0.35 * * *$ & $0.36^{* * *}$ & $0.37^{* * *}$ & $0.36^{* * *}$ & $0.38^{* * *}$ & $0.38^{* * *}$ & $0.37 * * *$ & $0.4 * * *$ & $0.45^{* * *}$ & $0.43^{* * *}$ & $0.47^{* * *}$ & $0.47^{* * *}$ \\
\hline Net $\mathrm{RCA}_{i k}$ & -0.167 & $-0.24 *$ & -0.05 & 0.04 & 0.06 & 0 & -0.02 & 0.03 & 0.02 & -0.03 & -0.05 & 0.06 & 0.16 & 0.14 & 0.19 & 0.13 & 0.18 \\
\hline Net $\mathrm{RCA}_{j k}$ & $0.368 * *$ & $0.29 * *$ & 0.17 & 0.14 & 0.1 & 0.17 & 0.12 & 0.04 & 0 & 0.02 & 0.02 & 0.06 & 0.01 & -0.19 . & -0.16 & -0.13 & $-0.21 *$ \\
\hline Time difference & -0.492 ** & -0.56 *** & $-0.53 * * *$ & $-0.63 * * *$ & $-0.6 * * *$ & $-0.47 * *$ & $-0.37 * *$ & $-0.41 * *$ & $-0.33 *$ & $-0.29 *$ & $-0.45 * *$ & $-0.46 * *$ & -0.26 . & -0.29 . & -0.25 . & -0.19 & -0.25 \\
\hline Common language & 0.154 & 0.1 & 0.23 & 0.23 & 0.26 & 0.2 & 0.32 & $0.36 *$ & 0.26 & 0.33 & 0.35 & $0.4 *$ & 0.41 * & 0.43 * & $0.37 *$ & $0.43 *$ & 0.39 * \\
\hline Colonial relationship & 0.462 & $0.57 *$ & $0.59 * *$ & $0.5 *$ & 0.39 & 0.37 & 0.47 * & 0.39 & 0.35 & 0.37 & 0.38 . & 0.25 & 0.15 & 0.2 & 0.2 & 0.18 & 0.29 \\
\hline Currency union & $-0.667 * *$ & $-0.75 * *$ & $-0.66 * *$ & $-0.62 *$ & -0.34 & -0.34 & -0.11 & -0.16 & -0.04 & -0.15 & -0.28 & -0.35 & -0.37 & $-0.66 *$ & & -0.17 & -0.19 \\
\hline Difference in latitude & -0.182 & -0.3 & -0.19 & -0.52 & -0.2 & 0.22 & 0 & 0.07 & 0.54 & 0.46 & 0.21 & -0.21 & 0.35 & 0.43 & 0.3 & 0.19 & 0.46 \\
\hline Common legal origin & $1.03 * * *$ & $1.06 * * *$ & $1.07 * * *$ & $1.09^{* * *}$ & $1 * * *$ & $0.94^{* * *}$ & $0.9 * * *$ & $1.03^{* * *}$ & $1.03^{* * *}$ & $1.07 * * *$ & $1.05 * * *$ & $1.07 * * *$ & $0.99^{* * *}$ & $1.1 * * *$ & $1 * * *$ & $1.04 * * *$ & $0.99 * * *$ \\
\hline Common border & $1.598 * * *$ & $1.43 * * *$ & $1.33 * * *$ & $1.4^{* * *}$ & $1.44 * * *$ & $1.42^{* * *}$ & $1.34 * * *$ & $1.49^{* * *}$ & $1.49^{* * *}$ & $1.49^{* * *}$ & $1.29^{* * *}$ & $1.11 * * *$ & $1.32 * * *$ & 1.29 *** & $1.33 * * *$ & $1.45 * * *$ & 1.35 *** \\
\hline Edges & $-9.01 * * *$ & $-8.51 * * *$ & $-8.72 * * *$ & $-8.74 * * *$ & $-9.18^{* * *}$ & $-9.19 * * *$ & $-9.19 * * *$ & $-9.26 * * *$ & $-9.84 * * *$ & $-9.67 * * *$ & $-9.19 * * *$ & $-8.91 * * *$ & $-10.19 * * *$ & $-13.98 * * *$ & $-13.56 * * *$ & -13.91 *** & $-14 * * *$ \\
\hline Observat & & & & & & & & & & & & & & 3 & & & 34,030 \\
\hline Al & $\begin{array}{l}34,030 \\
1964.16\end{array}$ & $\begin{array}{l}34,000 \\
1991.79\end{array}$ & $\begin{array}{l}34,030 \\
1961.49\end{array}$ & $\begin{array}{l}54,030 \\
1937.3\end{array}$ & $\begin{array}{l}34,030 \\
1909.68\end{array}$ & $\begin{array}{l}34,030 \\
1933.91\end{array}$ & $\begin{array}{l}34,030 \\
1968.23\end{array}$ & $\begin{array}{l}54,050 \\
2072.69\end{array}$ & $\begin{array}{l}54,050 \\
2037.65\end{array}$ & $\begin{array}{l}54,030 \\
1998.96\end{array}$ & $\begin{array}{l}34,030 \\
2071.68\end{array}$ & $\begin{array}{l}54,030 \\
2103.56\end{array}$ & $\begin{array}{l}2066.4 \\
2060.4\end{array}$ & $\begin{array}{l}24,030 \\
2016.95\end{array}$ & $\begin{array}{r}204,050 \\
2047.61\end{array}$ & $\begin{array}{l}2060.79 \\
2060\end{array}$ & $\begin{array}{r}24,050 \\
2052.22\end{array}$ \\
\hline & 2053.82 & 2081.45 & 2051.15 & 2026.96 & 1999.34 & 2023.57 & 2057.89 & 2162.35 & 2127.31 & 2088.62 & 2161.34 & 2193.22 & 2156.06 & 2106.61 & 2137.27 & 2150.45 & 2141.88 \\
\hline Triangles & 2009 & 2044 & 1863 & 1558 & 1396 & 1327 & 1559 & 1719 & 1792 & 1630 & 1692 & 1843 & 1839 & 1730 & 1808 & 1792 & 1634 \\
\hline
\end{tabular}

Note: This table explores the relation between M\&A flows, trade flows, and network variable. The dependent variable is equal to one if an M\&A transaction superior to 1 million US dollars occurred between two countries in the last 5 years in the light manufacturing sector. Total trade is measured as the sum of exports and imports. The GWESP indicator stands for geometrically weighted edgewise shared partner distribution and measures the likeliness of a common receiver country for two countries linked with an M\&A. Relative comparative advantage (RCA) is based on Vollrath (1991). All regressions include gravity control variables that help explain levels of M\&A flows between each country pair based on the differences in latitude between countries, differences in time zones, whether they share a common language, whether they have a common legal origin, and whether the receiver (sender) country is (or was) a colony of
the sender (receiver). Significance levels correspond to $* * * \mathrm{p}<0.001, * * \mathrm{p}<0.01, * \mathrm{p}<0.05$. Standard deviations are not reported. Sources: Calculations based on data from SDC Platinum and Comtrade. 
Table A12: Estimation of 5-year rolling M\&A superior to 1 million US dollars in Heavy Manufacturing determinants using ERGM procedure

\begin{tabular}{|c|c|c|c|c|c|c|c|c|c|c|c|c|c|c|c|c|c|}
\hline & 2000 & 2001 & 2002 & 2003 & 2004 & 2005 & 2006 & 2007 & 2008 & 2009 & 2010 & 2011 & 2012 & 2013 & 2014 & 2015 & 2016 \\
\hline GWESP & $1.729 * * *$ & $1.8^{* * *}$ & $1.9^{* * *}$ & $1.63^{* * *}$ & $1.66^{* * *}$ & $1.5^{* * *}$ & $1.57^{* * *}$ & $1.6^{* * *}$ & $1.5^{* * *}$ & $1.4^{* * *}$ & $1.49^{* * *}$ & $1.64^{* * *}$ & $1.92^{* * *}$ & $1.75^{* * *}$ & $1.65^{* * *}$ & $1.58^{* * *}$ & $1.58^{* * *}$ \\
\hline High Income $_{i}$ & $1.037 * * *$ & $1.15 * * *$ & $1.04 * * *$ & $1.05 * * *$ & $1.02 * * *$ & $0.87 * * *$ & $0.95 * * *$ & $0.95 * * *$ & $0.88 * * *$ & $0.85 * * *$ & $0.99 * * *$ & $0.82 * * *$ & $0.92 * * *$ & $1.08 * * *$ & $1.03 * * *$ & $0.75 * * *$ & $0.65 * * *$ \\
\hline Trade Openness $i_{i}$ & $0.48 * * *$ & $0.49^{* * *}$ & $0.46 * * *$ & $0.46^{* * *}$ & $0.42 * * *$ & $0.36 * * *$ & $0.33 * * *$ & $0.36 * * *$ & $0.39 * * *$ & $0.41 * * *$ & $0.4 * * *$ & $0.39 * * *$ & $0.37 * * *$ & $0.62 * * *$ & $0.61 * * *$ & $0.63^{* * *}$ & $0.58 * * *$ \\
\hline Net $\mathrm{RCA}_{i k}$ & -0.023 & -0.07 & 0.02 & 0.01 & 0.08 & $0.31 *$ & 0.17 & 0.11 & 0.15 & 0.18 & 0.14 & $0.28 *$ & 0.13 & $-0.26 *$ & $-0.31 *$ & -0.14 & -0.12 \\
\hline Net $\mathrm{RCA}_{j k}$ & $0.485 * * *$ & $0.83 * * *$ & $0.63^{* * *}$ & $0.9 * * *$ & $0.93 * * *$ & $1.08 * * *$ & $0.87 * * *$ & $0.86 * * *$ & $0.93 * * *$ & 0.96 *** & $1.01 * * *$ & $0.91 * * *$ & $1.02 * * *$ & $0.87 * * *$ & $0.78 * * *$ & $0.99 * * *$ & $0.91 * * *$ \\
\hline Time difference & $-0.657 * * *$ & $-0.68 * * *$ & $-0.71 * * *$ & $-0.74 * * *$ & $-0.62 * * *$ & $-0.52 * * *$ & -0.55 *** & $-0.52 * * *$ & $-0.39 * *$ & $-0.45 * * *$ & $-0.4 * *$ & $-0.36 * *$ & $-0.31 *$ & $-0.34 * *$ & $-0.31 *$ & -0.22 & $-0.34 *$ \\
\hline Common language & -0.044 & -0.05 & -0.01 & -0.05 & 0.11 & 0.1 & 0.07 & 0.07 & 0.03 & 0.01 & 0.14 & 0.23 & 0.33 & 0.13 & 0.01 & 0.13 & 0.19 \\
\hline Colonial relationship & $0.46 *$ & 0.47 . & $0.51 *$ & 0.44 & 0.2 & 0.02 & 0.19 & 0.23 & 0.32 & 0.38 & 0.32 & 0.21 & 0.18 & 0.27 & 0.4 . & 0.35 . & 0.44 . \\
\hline $\begin{array}{l}\text { Currency union } \\
\text { lilu }\end{array}$ & $-0.474 *$ & -0.42 & $\begin{array}{l}-0.42 . \\
-0.2\end{array}$ & $-0.42 *$ & -0.32 & $\begin{array}{l}-0.36 \\
-0.36\end{array}$ & $-0.67 * *$ & $-0.75 * * *$ & $-0.55 * *$ & $-0.61 * *$ & $-0.67 * * *$ & $-0.61 * *$ & $-0.7^{* *}$ & $-0.57 *$ & -0.42 . & -0.23 & -0.16 \\
\hline Difference in latitude & -0.16 & 0.57 & 0.38 & -0.05 & -0.39 & -0.17 & -0.13 & 0.24 & 0.71 & 0.57 & 0.67 & 0.66 & $0.98 *$ & $0.96 *$ & $1.07 *$ & $0.9^{*}$ & 0.75 \\
\hline Common legal origin & $1.519 * * *$ & $1.52 * * *$ & $1.43 * * *$ & $1.4 * * *$ & $1.23 * * *$ & $1.25 * * *$ & $1.22 * * *$ & $1.25 * * *$ & $1.34 * * *$ & $1.48^{* * *}$ & $1.37^{* * * *}$ & $1.34^{* * * *}$ & $1.29 * * *$ & $1.34 * * *$ & $1.37 * * *$ & $1.36 * * *$ & $1.29^{* * *}$ \\
\hline Common border & $1.126 * * *$ & 1.3 *** & 1.33 *** & $1.34 * * *$ & $1.28 * * *$ & $1.37 * * *$ & $1.33 * * *$ & $1.24 * * *$ & 1.26 *** & $1.3^{* * *}$ & 1.36 *** & $1.22 * * *$ & $1.24 * * *$ & $1.42 * * *$ & $1.4 * * *$ & $1.2 * * *$ & $1.03 * * *$ \\
\hline Edges & $-10.02 * * *$ & $-11.1 * * *$ & $-10.53 * * *$ & $-9.98 * * *$ & $-9.38 * * *$ & $-8.88^{* * *}$ & $-8.51 * * *$ & $-9.2^{* * *}$ & $-9.98 * * *$ & $-9.92 * * *$ & $-10.2 * * *$ & -10.19 *** & $-10.76 * * *$ & $-18.09 * * *$ & $-17.64 * * *$ & $-17.8^{* * *}$ & $-16.51 * * *$ \\
\hline Observations & 34,0 & 3 & & & & & & 3 & & & & 34,0 & 34, & 34,0 & 30 & 34,030 & 34,030 \\
\hline & 2552.74 & 2510.29 & 2523.66 & 2610.82 & 2678 & 2672.2 & 2907.86 & 3124.48 & 3309 & 327 & 3351.94 & 3289.36 & 3168.61 & & 2869.5 & 2803.1 & 2824.02 \\
\hline $\mathrm{BI}$ & 2642.4 & 2599.95 & 2613.32 & 2700.48 & 2768.44 & 2761.86 & 2997.52 & 3214.14 & 3399.04 & 3361.42 & 3441.6 & 3379.02 & 3258.27 & 2907.91 & 2959.16 & 2892.76 & 2913.68 \\
\hline Triangles & 5387 & 5702 & 5591 & 6009 & 5741 & 5230 & 5821 & 6838 & 7877 & 8144 & 8789 & 8209 & 7879 & 7039 & 6963 & 6512 & 6283 \\
\hline
\end{tabular}

Note: This table explores the relation between M\&A flows, trade flows, and network variable. The dependent variable is equal to one if an M\&A transaction superior to 1 million US dollars occurred between two countries in the last 5 years in the heavy manufacturing sector. Total trade is measured as the sum of exports and imports. The GWESP indicator stands for geometrically weighted edgewise shared partner distribution and measures the likeliness of a common receiver country for two countries linked with an M\&A. Relative comparative advantage (RCA) is based on Vollrath (1991). All regressions include gravity control variables that help explain levels of M\&A flows between each country pair based on the differences in latitude between countries, differences in time zones, whether they share a common language, whether they have a common legal origin, and whether the receiver (sender) country is (or was) a colony of
the sender (receiver). Significance levels correspond to ${ }^{* * *} \mathrm{p}<0.001, * * \mathrm{p}<0.01, * \mathrm{p}<0.05$. Standard deviations are not reported. Sources: Calculations based on data from SDC Platinum and Comtrade. 


\section{A3 Goodness of fit for TERGM results}

After running the TERGM, we estimate the goodness-of-fit and trace the MCMC plots of the statistically significant variables.

Figure A4: Primary sector
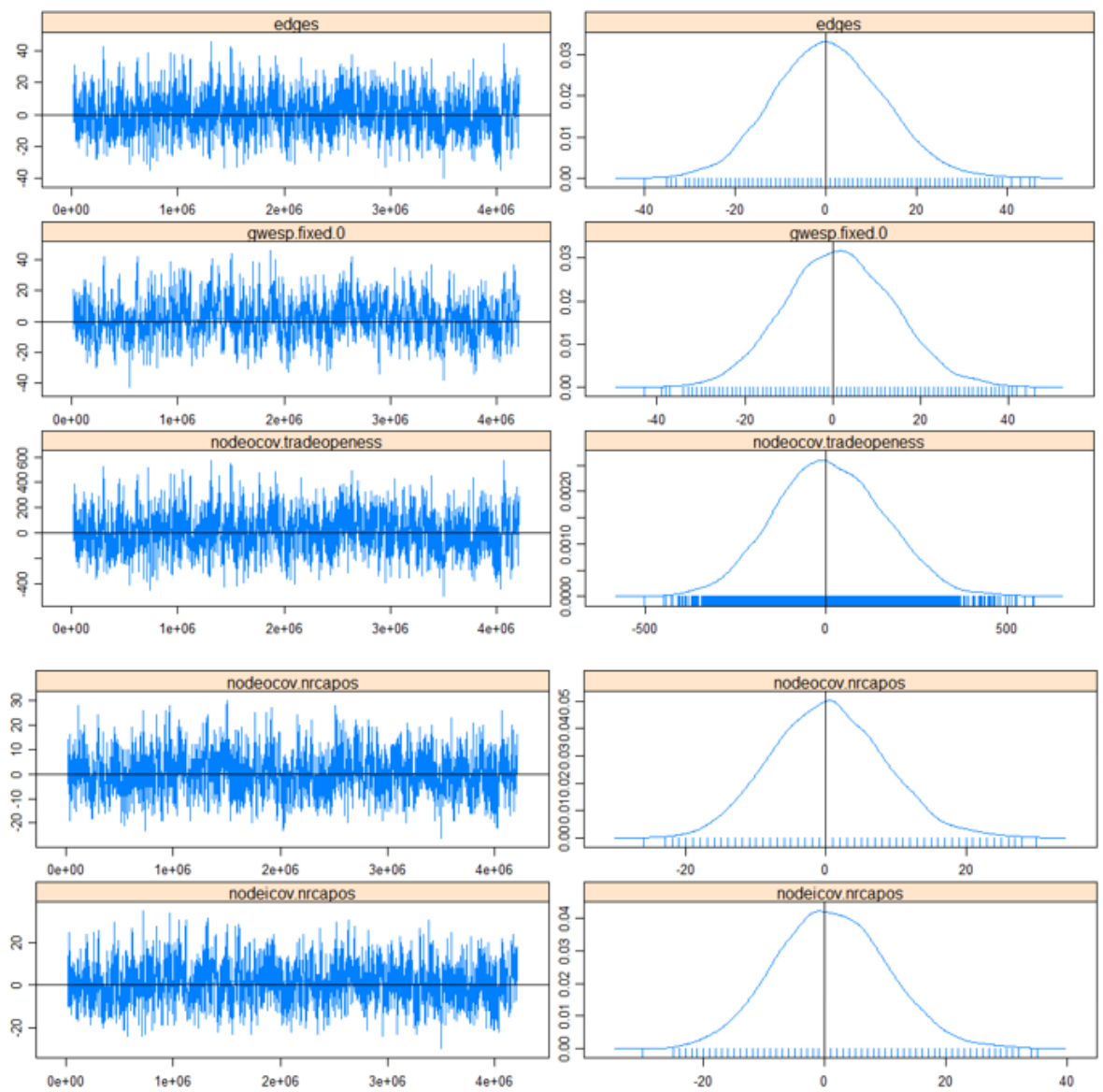
Figure A5: Light manufacturing
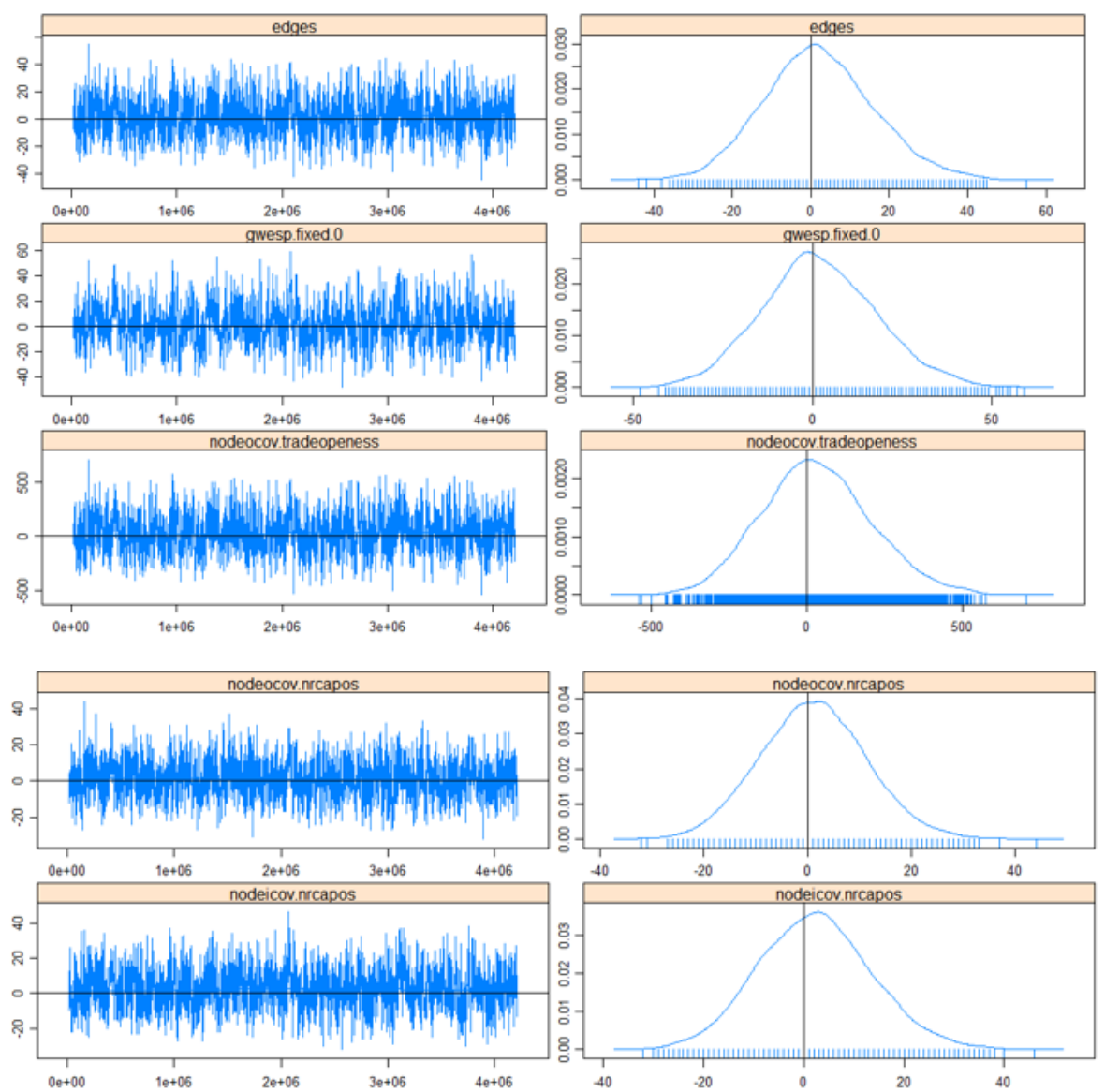
Figure A6: Heavy manufacturing
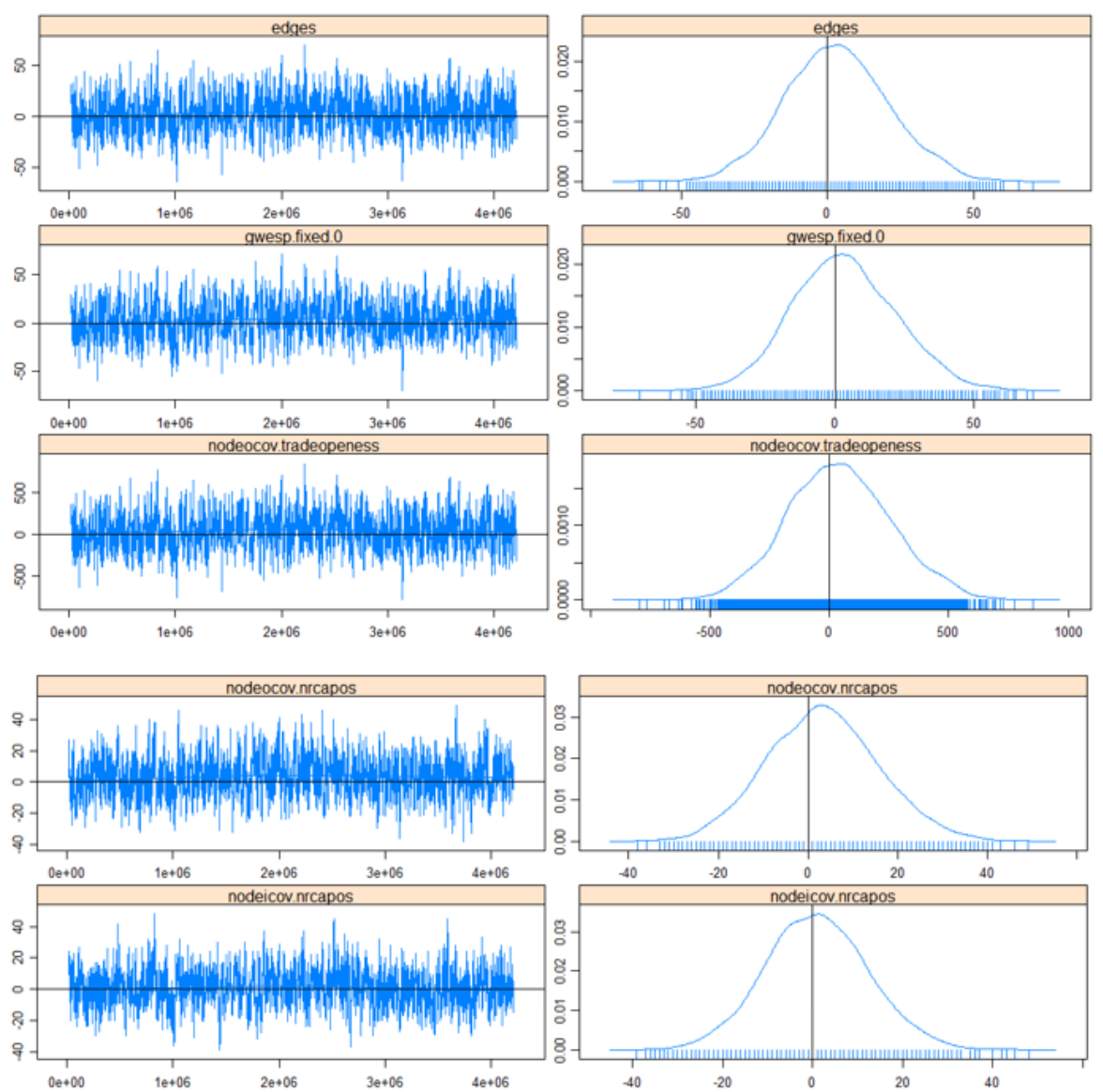